\title{
Del papel a la acción en la mitigación y adaptación al cambio climático: la
}

\section{roya del cafeto en Chiapas}

\section{From paper to action in climate change mitigation and adaptation: The case of the coffee rust in Chiapas}

\author{
Antoine Libert-Amico'* y Fernando Paz-Pellat2,3 \\ 1 Universidad Autónoma Metropolitana. Doctorado en 2 Colegio de Postgraduados. Campus Montecillo. Tex- 3 Programa Mexicano del Carbono.

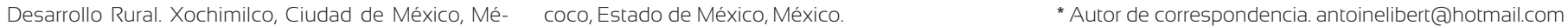
xico.

\section{RESUMEN}

En el proceso de reconocimiento de los desafíos múltiples que el cambio climático presenta para la sociedad y el ambiente, la cantidad de estudios, planes y programas que discuten la mitigación y adaptación ha aumentado exponencialmente. Si bien un problema complejo como el cambio climático requiere soluciones complejas, persisten barreras a visiones interdisciplinarias y a la coordinación intersectorial. En particular, proyectos de gabinete (el papel) difícilmente llegan a la etapa de implementación (la acción), mientras que pocos contemplan las sinergias entre mitigación y adaptación. Este trabajo analiza planes y programas de respuesta al cambio climático para el sector cafetalero en el contexto de la epidemia de roya del cafeto, enfermedad provocada por el hongo Hemileia vastatrix que ha generado pérdidas importantes en producción de café desde el ciclo 2012/2013. Problemas estructurales crearon condiciones idóneas para esta enfermedad asociada al cambio climático, a la vez que la respuesta institucional ha generado nuevos desafíos para las comunidades cafetaleras que viven en zonas de alta biodiversidad como la Sierra Madre de Chiapas en el sureste de México. El escrito discute las sinergias entre mitigación y adaptación al cambio climático por medio del análisis de la campaña a favor de los acervos de carbono y la biodiversidad en cafetales bajo sombra de la Sierra Madre de Chiapas. Diseñada en respuesta a la presente epidemia de roya del cafeto, dicha campaña pone énfasis en la deforestación, la degradación forestal y la pérdida de servicios ecosistémicos que ha generado la actual crisis del café bajo sombra, con propuestas de atención que beneficien tanto a ecosistemas como a comunidades cafetaleras. Se identifican tres desafíos que marcan la distancia entre el papel y la acción, ejemplificados en el caso de la crisis cafetalera de la Sierra Madre de Chiapas.

Palabras Clave: Hemileia vastatrix, planeación, REDD+, sinergias, sistemas agroforestales.

\section{ABSTRACT}

In the process of recognizing the multiple challenges that climate change presents to society and the environment, the number of studies, plans, and programs that discuss mitigation and adaptation has increased exponentially. Although a complex problem demands complex solutions, barriers to interdisciplinary visions and intersectoral coordination persist. Particularly, office-based projects (paper) rarely reach the implementation stage (action), while few contemplate the synergies between mitigation and adaptation. This article analyses climate change plans and programs for the coffee sector considering the coffee rust epidemic, a disease caused by the fungus Hemileia vastatrix which has generated important losses to coffee production since the 2012/2013 cycle. Structural problems created ideal conditions for this disease which has been associated with climate change, whilst the institutional response has generated new challenges for coffee producing communities who live in biodiversity hotspots like the Chiapas Sierra Madre in southern Mexico. We discuss the synergies between climate change mitigation and adaptation by analyzing the campaign in favor of carbon stocks and biodiversity in shade-grown coffee plantations of the Sierra Madre de Chiapas. Designed in response to the current coffee rust epidemic, this campaign emphasizes deforestation, forest degradation and loss of ecosystem services that is associated with the current crisis of shade-grown coffee, with proposals set out to benefit both ecosystems and the coffee communities. We identify three challenges which mark the distance between paper and action, as exemplified in the case of the coffee crisis in the Chiapas Sierra Madre.

Keywords: Hemileia vastatrix, planning, REDD+, synergies, agroforestry 


\section{INTRODUCCIÓN}

La cantidad de estudios, publicaciones y políticas interinstitucionales relacionadas con el cambio climático ha aumentado aceleradamente en las últimas dos décadas (Haunschild, Bornmann y Marx, 2016). Los debates sobre cambio climático tienden a enfatizar una de dos estrategias: la mitigación (reducción de emisiones y aumento de acervos de carbono) o la adaptación a los cambios ya en marcha ante el cambio ambiental global (Taylor, 2015). La separación entre mitigación y adaptación se ha diluido en años recientes, particularmente ante el reconocimiento de que aun si se lograse parar las emisiones de gases de efecto invernadero (GEI) mañana mismo, el tiempo de vida de los GEI ya emitidos hace que estos seguirán impactando el clima global por años (Clar, Prutsch y Steurer, 2013). Si bien la ciencia pone en evidencia que mitigación y adaptación deben ir de la mano, existen limitadas políticas enfocadas en las sinergias entre estas dos (Altieri y Nicholls, 2017; Kongsager, Locatelli y Chazarin, 2016).

Estudios del impacto del cambio climático en los sectores agrícolas y forestales han recibido interés particular (Jönsson et al., 2015). Sin embargo, resulta difícil identificar el vínculo entre la cantidad de estudios (y de fondos dedicados a estos) y una correspondiente modificación de políticas, programas y arreglos de gobernanza para hacer frente a los desafíos señalados (Lyle, 2015). Con la creación de nuevos programas de mitigación y adaptación al cambio climático, aumenta también la cantidad de fondos públicos y privados orientados a este fin, si bien los resultados han sido limitados: mientras la ciencia demuestra lo difícil que será mantenerse debajo de la meta de un aumento de $2{ }^{\circ} \mathrm{C}$ para el año 2100 (World Bank, 2012), se percibe que la sociedad aún no está preparada para lo que le espera a la vuelta de la esquina (Vink, Dewulf y Termeer, 2013). Conforme las metodologías de los escenarios futuros del cambio climático se han afinado -arrojando previsiones con grados de certidumbre en aumento- se percibe que la velocidad de adopción de cambios en las políticas y las prácticas ha quedado atrás, profundizando la brecha, evidencia cien- tífica y respuesta política (United Nations Development Programme [UNDP], 2007; Intergovernmental Panel on Climate Change [IPCC], 2014).

En relación con la mitigación del cambio climático, la estrategia global ha cambiado de gobernanza internacional regulatoria a contribuciones voluntarias: si bien el Protocolo de Kioto establecía un porcentaje común de reducción de emisiones para todas las Partes (países), el Acuerdo de París, firmado en 2015, favorece el esquema de "contribuciones previstas y determinadas a nivel nacional” (INDC por sus siglas en inglés). En este esquema, cada país determina y registra su propia contribución a la mitigación del cambio climático, sin que existan mecanismos de presión ni sanciones por no cumplimiento, con el objetivo general de limitar a $2{ }^{\circ} \mathrm{C}$ para el año 2100 el incremento de la temperatura (Convención Marco de las Naciones Unidas sobre Cambio Climático [Cmnucc], 2015). Por otra parte, cuando se habla de adaptación al cambio climático, se vuelve evidente, ante las desigualdades existentes, que las capacidades de adaptación no están repartidas equitativamente a través de diferentes actores de la sociedad (Picketty, 2014; Crédit Suisse, 2015). Munck af Rosenschöld, Rozema y Frye-Levine (2014) identifican una "inercia institucional" en responder a los efectos adversos del cambio climático y describen cinco mecanismos principales que contribuyen a dicha inercia: costos, incertidumbre, dependencia en opciones, poder y legitimidad. Sin embargo, no solo las instituciones expresan resistencia al cambio. Según Clément y Rivera (2017), las empresas en general tienden a contar con la habilidad para operar en ambientes desfavorables, pero enfrentan límites serios en la adaptación a la adversidad ecológica. Antwi-Agyei, Dougill y Stringer (2014) resaltan las capacidades limitadas de adaptación al cambio climático de pequeños productores que enfrentan barreras financieras, socioculturales, institucionales y tecnológicas, además de una falta de acceso a la información sobre las características del cambio climático y sus expresiones. Desagregar los obstáculos particulares (y las posibles ventajas también) que tenga cada actor será clave para enfrentar el desafío global (Boonstra, 2016). 
En México proliferan, en años recientes, los estudios, programas y planes que se refieren al cambio climático, con énfasis particular en la mitigación por medio de la lucha contra la deforestación (si bien es un país petrolero con altas emisiones asociadas a los combustibles fósiles), donde los planes enfatizan la reducción de emisiones en los bosques tropicales. Este trabajo analiza las acciones propuestas en el marco de la epidemia de la roya del cafeto, una epidemia que ha sido un determinante de deforestación y degradación forestal en zonas de alta biodiversidad (Covaleda, Aguilar, Ranero, Marín y Paz, 2014; Cooperativa AMBIO S. C., 2015; Libert-Amico, 2017). Partiendo de los documentos ("el papel”) de planes y programas de mitigación y adaptación federales, estatales, regionales y locales, se revisan las acciones propuestas en relación con la roya, así como la conservación o mejoría de la sombra, compuesta por el estrato arbóreo. La sombra de los cafetales representa importantes almacenes de carbono en la biomasa aérea y suelo, cuya pérdida puede ser evitada a través de acciones concretas que impulsen su mantenimiento e incremento, tal como se discute más adelante. Desde la perspectiva de "la acción", las afectaciones multidimensionales por roya en la economía regional, en las comunidades productoras de café y en los ecosistemas cafetaleros han motivado el impulso de estrategias de respuesta que enfatizan las sinergias entre mitigación y adaptación, con base en una iniciativa de investigación interdisciplinaria colaborativa entre redes de académicos, ejidos y cooperativas cafetaleras de la Sierra Madre de Chiapas, México.

Para analizar el "problema del encuadre" ("problem of fit"; Galaz, Olsson, Hahn, Folke, Svedin, 2008) entre papel y acción, se estudia la distancia entre planificación e implementación en el caso de la afectación por la roya del cafeto en México, en lo que algunos analistas han denominado un clásico ejemplo de "crónica de una devastación anunciada" (Barrera, Avelino, Huerta, Herrera y Gómez, 2013). La roya del cafeto, una enfermedad provocada por el hongo Hemileia vastatrix, ha generado severas afectaciones a la cantidad y calidad de la producción cafetalera en México, con un brote atípico iniciado en 2012 en la Sierra Madre de Chiapas (Libert-Amico, 2014). Parte de una epidemia regional, que inició en 2008 en Colombia y ha cubierto Mesoamérica y la región Andina (McCook y Vandermeer, 2015; Avelino et al., 2015), la presente afectación por roya ilustra los desafíos futuros que el cambio climático presenta para la agricultura familiar, con la previsión de un aumento en la vulnerabilidad a plagas y enfermedades (IPCC, 2014). En un ambiente discursivo en el cual se habla mucho de la preparación ante los desafíos por venir, el caso de la epidemia de roya presenta un caso ejemplar para analizar la distancia entre preparación y acción ante desafíos asociados al cambio climático ya presentes.

Tras presentar el contexto de los sistemas agroforestales y el cambio climático, se discuten los estudios en México ante el cambio climático y la crisis estructural del sector cafetalero, antes de la epidemia de la roya del cafeto que inició a finales de 2012. En relación con las acciones tomadas ante la roya, se analizan los costos de la maladaptación por medio de un diagnóstico de los programas bajo implementación por parte de organismos públicos en asociación con algunas empresas comercializadoras de café. Dicho diagnóstico provee insumos para proponer una serie de acciones, en aras de una toma de decisiones informada y un diálogo colegiado entre productores de café, ciencia, y políticas gubernamentales.

\section{Contexto}

\section{La relación compleja entre agricultura y cambio climático}

La agricultura ha sido identificada como principal emisor de GEI, consumidor de importantes cantidades de agua y determinante de deforestación y degradación forestal por medio de la ampliación de la frontera agropecuaria (Godfray y Garnett, 2014; IPCC, 2014). Los monocultivos industrializados en extensas superficies son consumidores principales de recursos finitos como tierra (un tercio de las tierras arables del globo se emplean para producir alimento pecuario - Schader et al., 2015), agua (Morison, 
Baker, Mullineaux y Davies, 2008) y nitrógeno (Galloway et al., 2008). En el contexto de la sexta extinción masiva de especies (Kolbert, 2014), la población global depende de solo tres cultivos (arroz, trigo y maíz) para más de 50\% de las calorías provenientes de plantas, lo que deja vulnerable el suministro de alimentos ante plagas y enfermedades (Bioversity International, 2017).

Ante el desafío de alimentar una población en crecimiento acelerado, la agricultura es un determinante clave del cambio ecológico global, a la vez que es profundamente vulnerable ante el cambio climático (Rockström et al., 2016). El Intergovernmental Panel on Climate Change [IPCC] (2014) señala las afectaciones del cambio climático en la agricultura, particularmente en la pequeña producción familiar, debido al cambio de zonas aptas para los cultivos y una mayor vulnerabilidad ante plagas y enfermedades. Con aproximadamente 570000000 de hogares a escala planetaria, la pequeña producción familiar en parcelas de 2 ha o menos ocupa $75 \%$ de las tierras agrícolas (Lowder, Skoet y Raney, 2016). En México, la pequeña agricultura familiar (menor o igual a 5 ha) representa $68 \%$ de las más de 4000000 de unidades de producción registradas en México (Robles, Suárez y de la Mora, 2015). La pequeña unidad campesina trabaja $17 \%$ de la superficie laborable del país, donde genera $40 \%$ de la producción agropecuaria nacional y $60 \%$ del empleo agropecuario familiar y contratado (Robles et al., 2015; Concheiro y Robles, 2014). En contraste con amplias extensiones de cultivos estandarizados para facilitar la productividad con base en maquinaria e insumos externos, existen formas de producción agrícola que han sido identificados por sus potenciales aportaciones ante los desafíos del cambio climático. La agroforestería - entendida como un conjunto diversificado de sistemas de producción agrícola que integra árboles en el ecosistema agrícola - provee servicios ecosistémicos claves como la polinización (Imbach et al., 2017), la captura de carbono (Zomer et al., 2016), la conservación de suelos (Atangana, Khasa, Chang y Degrande, 2014) y la biodiversidad (Bioversity International, 2017). En 2010, la agroforestería representaba $43 \%$ de las tierras agrícolas a escala global: casi 1000000000 ha agrícolas cuentan con $10 \%$ o más en cobertura de sombra arbórea (Zomer et al., 2016).

La agroforestería también representa un espacio clave para la agrobiodiversidad; es decir, la variedad y variabilidad de animales, plantas y micro-organismos que contribuyen directa o indirectamente a la alimentación y agricultura (Qualset y Shands 2005). La pérdida de agrobiodiversidad pone en riesgo no solo la nutrición y salud humana, pero también la sustentabilidad y resiliencia de los sistemas alimenticios (Bioversity International, 2017). El café producido en sistemas agroforestales (arbustos de café cultivados bajo la sombra de árboles) es un ejemplo del potencial de los agroecosistemas para cumplir de manera sincrónica con los objetivos de mitigación del cambio climático (reducción de emisiones y conservación de almacenes de carbono) y adaptación (fomentando biodiversidad, generando ingresos para pequeños productores, y fortaleciendo la resiliencia de paisajes de montaña sujetos a degradación y vulnerabilidad ante eventos extremos meteorológicos) (Altieri y Nicholls, 2017; Lasco, Delfino y Espaldon, 2014). Los cafetales bajo sombra almacenan cantidades de carbono comparables con la vegetación natural (Soto, Anzueto, Mendoza, Jimenez y de Jong, 2010; van Rikxoort, Schroth, Läderach y Rodríguez-Sánchez, 2014; Soto y Aguirre, 2015), con una riqueza de especies de plantas que se asemeja a los bosques y selvas que los albergan (Moguel y Toledo, 1999; Soto, Romero, Caballero y Segura, 2001). La sombra de los cafetales tiene múltiples servicios ambientales, incluyendo la amortiguación del estrés climático y el desbalance nutricional (Barradas y Fanjul, 1984; Beer, Muschler, Kass y Somarriba, 1998; López, Sotomayor, Amador y Shröder, 2015), mantenimiento de la biodiversidad (Rojas, Hartman y Almonacid, 2012; González, Enríquez, Rangel, García y Tejeda, 2012; Soto, 2013), fortalecimiento de sistemas de producción locales y medios de vida (Escamilla et al., 2005; Méndez y Bacon, 2006; Toledo y Moguel, 2012), entre otros.

Los ecosistemas cafetaleros tienen una distribución bimodal en su estructura y forma de producción: arbustos de café sembrados en monocultivos con exposición libre al 
sol (una forma de producción que tiende a crecer) o café bajo sombra; es decir, cafetos que crecen bajo un estrato arbóreo que le genera sombra (Vandermeer y Perfecto, 2012). Aunque la mayoría de las superficies cafetaleras en el mundo aún siguen siendo de Coffea arabica cultivado bajo algún tipo de sombra, políticas gubernamentales en respuesta a plagas y enfermedades en el marco de la Revolución Verde han sido fuertes impulsos hacia la producción intensiva, provocando una reducción de este sistema agroforestal en 20\% de su superficie global desde 1996 (Jha et al., 2014). Si bien ha bajado su importancia global en la cantidad de sacos de café producidos, la forma de producción de café en México sigue siendo mayoritariamente de Coffea arabica, cultivado bajo sombra diversa y con importantes contribuciones a los nichos de mercado especializados, en lo que algunas cooperativas de la zona de estudio (Sierra Madre de Chiapas) llaman "café de conservación": orgánico, amigable con las aves y de pequeños productores.

Este tipo de agroforestería es una actividad predominante de la zona de estudio del presente artículo: en los 22 municipios de la Sierra Madre de Chiapas el café bajo sombra diversificada es manejado por pequeños productores cuyas parcelas cuentan con una superficie promedio de 1.77 ha $^{1}$. La Sierra Madre de Chiapas constituye una ecorregión al compartir historia, actividad productiva (café bajo sombra), identidad, cultura, e incluso lazos familiares (debido a la particular forma de colonización de esta región montañosa a través de fincas cafetaleras y la posterior reforma agraria) (Libert-Amico, 2017). La región ha sido designada como "Corredor Biológico Sierra Madre del Sur, Chiapas" por parte del gobierno federal y también forma parte del Corredor Biológico Mesoamericano bajo la tutela de la Comisión Nacional para el Conocimiento y Uso de la Biodiversidad [Conabio].

1 Cálculo propio con base en el Padrón Nacional Cafetalero de 2014, que contabilizó en ese año 49579 beneficiarios en el estado de Chiapas (34.68\% del padrón nacional). En realidad, se estima que la superficie promedio será ligeramente mayor, ante inconsistencias en lo que los productores registran ante el padrón, errores en el levantamiento de datos y el hecho que productores que participan en cooperativas de café no indican dichos cafetales en el padrón en cuestión.
Un estudio de la cafeticultura en la región mesoamericana resaltó la particular relevancia de la producción de café en la Sierra Madre de Chiapas, donde el manejo "tradicional en agrobosques de café con complejos doseles de sombra" suministra importantes servicios ambientales: sumideros de carbono, hábitats para la biodiversidad, servicios hidrológicos, conservación de suelos y regulación térmica (Läderach et al., 2013). Läderach et al. (2013) alertan sobre la vulnerabilidad de dichos ecosistemas agrícolas:

"las presiones del mercado y del clima han obligado a simplificar muchos sistemas de producción en la regiónuna estrategia contraproductiva que destruye, en vez de desarrollar capacidad adaptativa a futuros cambios climáticos. A medida que las fincas cafetaleras no rentables abandonen este cultivo, es muy probable que se le den otros usos a la tierra, resultando en la fragmentación y pérdida del hábitat de agrobosque. Se teme que los incentivos futuros lleven al deterioro del ecosistema" (Läderach et al., 2013: 33-34).

\section{Roya y cambio climático}

El hongo Hemileia vastatrix comparte el endemismo con su hospedero, la planta de café; es decir, los dos organismos son originarios de las colinas de Etiopía y han convivido por siglos. En lo que McCook y Vandermeer (2015) han llamado "una cuarentena involuntaria", al parecer el hongo de la roya no sobrevivió el paso del cafetal por la Península Arábica antes de ser difundido como plantación colonial a través del globo, primero por el imperio otomano y luego por comerciantes venecianos y holandeses en el siglo XVI. Sin embargo, el comercio transoceánico del siglo XIX no tardaría mucho en difundir la roya por medio de sus embarcaciones coloniales. La roya fue "bautizada" por la ciencia occidental como Hemileia "devastadora" (vastatrix en latín) tras la destrucción de los cafetales de la isla de Ceilán (hoy Sri Lanka) en 1869. La roya llegaría eventualmente a Brasil 100 años después, cubriendo paulatinamente los cafetales de América Latina hasta su llegada al Soconusco, Chiapas, en 1981. Transportado por los vientos, en las plantas distribuidas, o en la 
misma ropa y herramientas de trabajadores migrantes, hoy en día el hongo se ha difundido por todos los cafetales del mundo (Bebber, Castillo y Gurr, 2016).

Al contrario de lo esperado, el arribo de la roya a los cafetales de América Latina no tuvo los impactos devastadores pronosticados en un primer momento (McCook y Vandermeer, 2015). Sin embargo, la roya generó en la década de los 1990s epidemias puntuales y localizadas con severas afectaciones en la producción, tal como en Costa Rica en 1989-1990, Nicaragua en 1995-1996 y Honduras en 1995-1996 (Avelino, Muller, Eskes, Santacreo y Holguín, 1999). A pesar de esto, la roya dejó de ser parte de la agenda nacional e internacional. Avelino et al. (1999) argumentaron la necesidad de considerar la roya como una cuestión de vigilancia y atención constante: “Más de 20 años después [de su arribo a la región], la roya anaranjada ya no es un mito, es una realidad, bien establecida en el paisaje centroamericano, que amerita una atención permanente del sector cafetalero".

Los limitados impactos de la roya y la influencia de otras plagas de importancia económica para el cafeto (la más renombrada en la zona siendo la broca, Hypothenemus hampei), junto con la desaparición del Acuerdo Internacional del Café y la consecuente liberalización del mercado del café, hicieron que la roya dejara de ser un punto de atención (McCook y Vandermeer, 2015).

Entre 2008 y 2011 la roya se manifestó en una epidemia que devastó la producción de café en Colombia (Rozo, Escobar, Gaitán y Cristancho, 2012). En una serie de brotes atípicos asociados al evento climatológico de la "Ola Invernal” de los años 2008-2012 esta epidemia generó pérdidas de hasta $31 \%$ en la cosecha colombiana (Avelino et al., 2015). Pocos años después, la roya se manifestaría en brotes atípicos a través de Centroamérica y el Caribe, con graves impactos en la producción de café y la economía regional, particularmente dependiente del café. Para la temporada de lluvias de 2012, la roya afectó severamente todas las zonas productoras de café de Mesoamérica. El hongo sorprendió productores arriba de la cota de $1200 \mathrm{~m}$ sobre el nivel del mar (límite histórico de la plaga), mientras generaba pérdidas severas en Chiapas, Guate- mala, Honduras, Nicaragua y Costa Rica (Barrera et al., 2013). La afectación por roya en el ciclo 2012-2013 llevó a cinco países centroamericanos a declarar el brote como emergencia nacional: con 55\% de afectación por roya de la superficie total dedicada al cultivo en Centroamérica, donde los cálculos iniciales estimaban pérdidas en la producción por casi 500000000 de dólares en dicho ciclo (Promecafe - Instituto Interamericano de Cooperación para la Agricultura [IICA], 2013).

Mientras reducían la producción regional de café Arábica y miles de empleos se perdían a través de la región (aumentando la presión sobre los flujos de migración), el comportamiento atípico de la roya se expandía. Hacía el sur, la epidemia se expresó en los cafetales de Ecuador y Perú a partir de 2013, mientras que en 2015 se denunciaba su impacto en la producción cafetalera de Bolivia. Hacía el norte, la epidemia - que ya estaba marcando estragos en los cafetales de las islas caribeñas - recorrió de Veracruz hasta Hidalgo y Nayarit. En el ciclo 2015-2016 productores de Oaxaca y Guerrero sufrieron pérdidas de hasta $95 \%$ debido a la roya, lo que generó serios riesgos a la seguridad alimentaria para pequeños productores marginados. En una cosecha históricamente baja que marcó la salida de México del "top ten” a escala global en volumen de producción, México importó en 2015/2016 más café del que produjo (International Coffee Organization [ICO], 2017).

Un dato clave es también preguntarse qué parámetros marcaron el brusco cambio en el comportamiento de una enfermedad presente en los cafetales desde décadas. La hipótesis de la evolución genética de la roya (es decir, que esta roya sea una raza nueva) es plausible, un derivado natural del encuentro entre el hongo y nuevos ecosistemas (e.g., alturas más pronunciadas y nuevas variedades de café) y prácticas diferentes de control y manejo. Si para 1975 investigadores del Centro de Investigaciones de la Roya del Café (CIFC por sus siglas en portugués) habían registrado 14 razas fisiológicas de la roya (Rodrigues Jr., Bettencourt y Rijo 1975), en 2012 se encontraban 49 razas. En 2017, un investigador mexicano identificó 58 patotipos (razas fisiológicas) de la roya (Solano-Vidal, 
2017). Aparte de una posible evolución genética de la roya, es plausible que cambios en el entorno sean factores claves. Vista la cobertura de la epidemia, no pareciera una cuestión localizada (Baker, 2014; Avelino et al., 2015). Es así como mucha atención se ha puesto en el papel del cambio climático, con la hipótesis de la presente epidemia de la roya como expresión de las plagas y enfermedades que el cambio ambiental global generará (IPCC, 2014).

Los impactos de la roya, a la par con el aumento constante en la demanda de café, ha fomentado la búsqueda de variedades de Coffea spp. tolerantes a la enfermedad. La crisis de la roya en el sureste asiático llevó a la identificación en África y el posterior desarrollo de Coffea canephora P., una especie cuya variedad mejor conocida es robusta (McCook, 2013). Este café es resistente a la roya y a otras plagas de importancia económica, aunque también tiene sus predadores naturales. La plantación de robusta se distingue por ser cultivado con poca o nula sombra, por debajo de la cota de $800 \mathrm{~m}$ snm, con una mayor productividad y un alto contenido en cafeína. Sin embargo, una baja calidad del grano en sus características organolépticas marca el precio inferior que recibe este café en el mercado internacional (aproximadamente un tercio del precio del C. arabica), donde este café es empleado en mezclas del aromático y en la producción de café soluble y bebidas energéticas.

Tras cambiar los cafetales de los continentes africanos y asiáticos de C. arabica a C. canephora, se descubrió un híbrido natural en la isla de Timor que mezclaba genes de la primera especie con genes de resistencia a la roya de la segunda. Este "hibrido del Timor" se convertiría en el ancestro de una serie de variedades resistentes a la roya en promoción hoy en día, con diversos cruces genéticos que buscan mantener los genes de resistencia a la roya y mejorar la calidad en taza de este tipo de cafetal (EscamillaPrado, Ruiz-Rosado, Zamarripa-Colmenero y González-Hernández, 2016; van der Vossen, Bertrand y Charrier, 2015).

Las variedades más conocidas en México de la familia Catimor (que deriva del cruce genético entre C. arabica variedad Caturra y el híbrido de Timor) incluyen Costa
Rica-95 (desarrollado en dicho país en 1995), Lempira (Honduras) y Oro Azteca (una variedad desarrollada en México por INIFAP) (Escamilla et al., 2016). Estas variedades se caracterizan por ser de porte bajo, precoces (pueden empezar a producir a los tres años, mientras que su vida útil también es reducida), con alta productividad (produce más granos, aunque estos tienden a pesar menos) y exigentes desde el punto de vista nutricional. A pesar de expresar una aumentada tolerancia frente a la roya, estas variedades han recibido críticas por parte de los tostadores internacionales de café por su baja calidad en taza. Tal como argumenta McCook: "hasta ahora los cafés resistentes no han sido precisamente una panacea de cara al problema de la roya" (McCook, 2009).

Una característica fundamental de estas variedades es que no toleran la producción de altura bajo sombra, ya que son susceptibles a otras enfermedades micóticas como "ojo de gallo" (provocada por el hongo Mycena citricolor), Cercosporiosis, o Antracnosis, aunque existe poca información sobre estas enfermedades (Ruiz et al., 2013). Estas variedades resistentes a la roya se cultivan bajo un porcentaje reducido de sombra, lo que implica la tala de la sombra al cambiar de variedades. De esta manera, estudios recientes han identificado el cambio de variedad en los cafetales como un determinante de deforestación y degradación forestal (Covaleda et al., 2014), un punto central que se discute más adelante.

\section{El papel: planes de mitigación y adaptación}

\section{México en las primeras filas de la lucha contra el cambio climático}

México ha puesto énfasis en demostrar a escala internacional que está en las primeras filas de la lucha contra el cambio climático. México fue entre los primeros a escala mundial en adoptar una Estrategia Nacional de Cambio Climático, junto con una Ley General sobre Cambio Climático que entró en vigor en 2012. Con las discusiones sobre REDD+ (Reducción de la Deforestación y Degradación forestal más conservación, incremento en los almacenes de carbono y manejo forestal sostenible), el país 
enarboló velozmente una serie de reformas legales para "cuadrar" el marco legal nacional con los requisitos internacionales (Carrillo y Ramírez, 2016).

En 2010, México presentó ante la $16^{\text {a }}$ Conferencia de la Partes (COP16) de la Convención Marco de las Naciones Unidas sobre Cambio Climático [Cmnucc] en Cancún el posicionamiento Visión de México sobre REDD+: Hacia una Estrategia Nacional. Posteriormente la administración federal desarrolló su Estrategia Nacional ante $R E D D+($ ENAREDD+), organizando una consulta nacional antes de divulgar la versión final en 2017 (Comisión Nacional Forestal [Conafor], 2017). Desde la participación de gobiernos estatales en el Governor's Climate and Forest Task Force (GCF), hasta la negociación de la Iniciativa de Reducción de Emisiones (IRE) ante el Forest Carbon Partnership Facility (FCPF) del Banco Mundial, el país se ha mostrado como líder a escala internacional en el diseño y la implementación de proyectos de preparación hacia REDD+.

Las reformas y adaptaciones al marco legal e institucional en el país corresponden seguido a requisitos de financiadores internacionales de acciones de preparación $\mathrm{y}$ fortalecimiento institucional para hacer frente al cambio climático. Instituciones financieras internacionales marcan la pauta de los procesos de arreglos institucionales, particularmente en el contexto de las discusiones sobre REDD+, donde la Cmnucc estableció ciertos requerimientos para poder entrar en este mecanismo financiero aún en discusión. Estos requisitos incluyen: 1) la promulgación de una Estrategia Nacional para REDD+ (ENAREDD+) debidamente consultada, 2) el establecimiento de los niveles de referencia (línea base) por medio del Inventario Nacional Forestal y de Suelos (INFyS) y sus versiones estatales correspondientes, 3) un sistema nacional de Monitoreo, Reporte y Verificación (MRV) y, 4) un sistema nacional de información sobre las Salvaguardas Sociales y Ambientales. En México, estos últimos dos puntos están en proceso, mientras que la ENAREDD+ fue divulgada en 2017 y los Inventarios Forestales Estatales están siendo elaborados para complementar el INFyS que ya ha sido actualizado (Libert-Amico y Trench, 2016).
En este contexto de nuevos marcos legales y arreglos institucionales, fondos internacionales y discusiones sobre programas y proyectos futuros de respuesta al cambio climático, se generaron en el país una gran cantidad de estudios, proyectos y programas.

\section{Los planes y programas en Chiapas relacionados} con el café: desde lo nacional a lo local

La ENAREDD+ establece el manejo integrado del territorio orientado al desarrollo rural sostenible, lo que implica la necesidad de colaboración entre el sector forestal y el agropecuario, entre otros (Conafor, 2017). Bajo los lineamientos del FCPF del Fondo de Carbono del Banco Mundial, la Comisión Nacional Forestal está en la fase de inicio de la implementación de la Iniciativa de Reducción de Emisiones o IRE (Conafor, 2016), que plantea el pago por reducir emisiones por actividades de evitar deforestación (y degradación forestal). En el caso de Chiapas, las regiones de implementación propuestas inicialmente incluyen: Fraylesca, Istmo-Costa, Selva Lacandona y Zoque-Mezcalapa (Conafor, 2016). Los programas de inversión en la Sierra Madre de Chiapas (Cooperativa AMBIO S. C., 2015; Kibeltik Clima y Medio Ambiente A. C., 2016) reconocen el problema de la roya del café y la necesidad de conservar la sombra bajo estrategias de renovación de cafetales usando viveros de variedades arábigas compatibles con el manejo bajo sombra. Aunque se ha obtenido el reconocimiento de la Conafor del problema de la roya como motor de la deforestación y degradación forestal, requiriendo inversiones específicas para implementar acciones concretas, aún no queda claro si la IRE considerará esta opción o si habrá financiamiento disponible, particularmente relacionado a acciones ex ante y pagos ex post (Skutsch, Balderas-Torres y Carrillo-Fuentes, 2017).

Por otro lado, la Comisión Nacional de Áreas Naturales Protegidas [Conanp] estableció el programa de adaptación en áreas naturales protegidas de la Sierra Madre con 35 estrategias de adaptación por tipo de ecosistema (Comision Nacional de Areas Naturales Protegidas [Conanp] - Fondo Mexicano para la Conservacion de la 
Naturaleza, A. C. [FMCN] - TNC, 2011). En el caso del bosque mesófilo de montaña, con cafetales bajo sombra, plantea la necesidad de establecer pagos por servicios ambientales por conservación y restauración y el café de conservación (sombra), entre otras acciones. Este programa, planteado antes del brote atípico de la roya en el 2012, ha tenido incidencia limitada en la gestión del problema de la roya, por escasez de recursos disponibles por la institución. ${ }^{2}$

El Gobierno de Chiapas (2011) fue uno de los primeros en desarrollar su Programa de Acción Ante el Cambio Climático del Estado de Chiapas (PACCCH), donde se plantean diversas acciones de mitigación y adaptación, incluido el tema de REDD+, la gestión de riesgos climáticos y la diversidad productiva, entre otras. Aunque el programa define actores para las líneas estratégicas y acciones, la falta de recursos de este programa para su implementación lo deja solo como un documento guía, en el mejor de los casos. La falta de una visión integral de desarrollo en el estado se refleja en sus programas regionales 2013-2018 de desarrollo (Gobierno de Chiapas, 2013), donde se plantean 13 proyectos estratégicos, con uno solo que propone la reforestación y conservación en una cuenca hidrográfica, sin relacionarlo con el tema de mitigación o adaptación, ni considerar el ecosistema cafetalero ni el impacto de la roya, ya evidente en esa fecha. No obstante, en el borrador de la Estrategia Estatal REDD+ (Ranero et al., 2017) se plantea la necesidad de realizar una gestión de la roya bajo la perspectiva de evitar las pérdidas de la sombra (carbono) al introducir variedades de café a sol. Para inicios de 2018, esta estrategia está aún en revisión y no cuenta con recursos financieros para su implementación.

El PACCCH (Gobierno de Chiapas, 2011) planteó estrategias de adaptación usando simulaciones de escenarios climáticos para fundamentar sus propuestas de estrategias y acciones. Respecto a la cafeticultura de la Sierra Madre de Chiapas se han realizado ejercicios similares (Schroth et al., 2009; CI México A. C., 2011; Baca et al., 2012), que plantean estrategias de adaptación como la

2 De 2015 a 2017, el presupuesto del sector ambiental en México sufrió un recorte del 50\% (Cemda, 2016). renovación de cafetales con variedades resistentes a plagas y enfermedades, gestión de la sombra y diversificación productiva. Ejercicios de modelación climática para la región afirman que la Sierra Madre de Chiapas, que cuenta hoy en día con 265400 ha en áreas óptimas para café arábigo, podría para 2050 referir a solamente 6000 ha en áreas óptimas para café de calidad, lo que sugiere que la zona está en riesgo de dejar de ser una fuente de café de especialidad (Schroth et al., 2009). Dados los análisis espaciales asociados a los escenarios climáticos, se ha planteado la necesidad de zonificar la región y definir las variedades apropiadas correspondientes (Schroth et al., 2009; CI México A.C., 2011). En la gestión de riesgos climáticos (un componente de la adaptación al cambio climático) se ha propuesto el uso de seguros para compensar los impactos climáticos en los cafetales (Schroth et al., 2009), así como el establecimiento de un fondo financiero común para café y cambio climático y el desarrollo de bonos de carbono y pagos por servicios ambientales (CI México A.C., 2011). Según Läderach et al. (2013), solo $10 \%$ del área dedicada a la producción de café en México está asegurada debido a los altos costos de los seguros disponibles.

El problema de la renovación de cafetales (la mayoría viejos y poco productivos), así como la gestión de plagas y el manejo de la sombra de los cafetales se han definido como de alta prioridad dentro del Plan de Innovación de la Cafeticultura en el Estado de Chiapas (CRUO-UAChINCA Rural-Amecafé-Sistema Producto Café, 2011), donde el plan identificaba en 2011 "un profundo problema de envejecimiento de cafetales". En la realidad existe poca investigación en el país sobre las diferentes variedades y sus ventajas y desventajas.

La Estrategia del Sector Cafetalero para la adaptación, mitigación y reducción de la vulnerabilidad ante el cambio climático en la Sierra Madre de Chiapas, dada a conocer un año antes del brote inicial de roya, identifica una serie de amenazas a la cafeticultura de la región, si bien apenas menciona en una ocasión la roya (CI México A.C., 2011). Por su parte, ejercicios de elaboración de planes de adaptación al cambio climático impulsados por 
organizaciones ambientalistas en colaboración con cooperativas de café de la Sierra Madre de Chiapas (Alfaro y Linne, 2008; Aguilar y Amezcua, 2013a; 2013b) identifican en la roya el principal ejemplo de la amenaza de las plagas y enfermedades, quizá porque su elaboración coincidió con el inicio del brote. Sin embargo, las cooperativas en cuestión indicaron que dichos planes no fueron implementados, si bien uno de estos documentos concluye: "Las propuestas que se realizaron llevan el objetivo de disminuir la vulnerabilidad y los riesgos ante el cambio climático en las parcelas de café de los socios de la cooperativa y dan respuesta a sus principales preocupaciones y carencias” (Aguilar y Amezcua, 2013b). Estos esfuerzos, junto con las iniciativas de la Alianza México-REDD+ en Chiapas entre 2013 y 2017, se enfocaron en buenas prácticas, un elemento clave sin duda, pero que puede enfrentar una difusión limitada y no toca la esfera de las políticas gubernamentales y cuestiones estructurales. A través de estos registros se diagnostica un sector en crisis, con problemas estructurales que lo vuelven vulnerable ante los escenarios del cambio climático. Plantaciones viejas (CRUO-UAChINCA Rural-Amecafé-Sistema Producto Café, 2011), falta de acceso a crédito (Dalberg, 2012), inexistencia de seguros (Läderach et al., 2013), junto con una tendencia hacia la productividad por medio de la reducción de la diversidad y de la complejidad de las especies útiles empleadas en los sistemas agroforestales del café, ponen en riesgo no solo los ecosistemas sino también la economía local, la organización comunitaria y la diversificación de ingresos para sectores marginalizados de la sociedad.

La revisión de los planes y programas de adaptación al cambio climático plantean que existían elementos suficientes de conocimiento sobre los efectos de la roya de los cafetales y el manejo de la sombra, con acciones propuestas y alternativas financieras (bonos de carbono, pago por servicios ambientales) para el posible financiamiento de la adaptación. Aunque el brote atípico de la roya se presentó en el 2012, un año anterior ya se contaba con los elementos para la construcción de una política pública acorde a los pronósticos. Sin embargo, la brecha entre ciencia y práctica, información y acción, se expresa en que estos ejercicios de papel no tuvieron impacto ni permitieron alinear esfuerzos y recursos sectoriales (federales, estatales y municipales).

\section{La acción: roya en la Sierra Madre}

\section{Los costos de la maladaptación}

En el ciclo 2011/2012 del cultivo de café se esperaba una recuperación de la cosecha nacional tras problemas asociados a precios y al clima (sequia) (Fideicomisos Instituidos en Relación con la Agricultura [FIRA], 2012). Después del impacto de la roya en los cafetales del país, en el ciclo 2016/2017 los pronósticos eran desalentadores, con una baja pronunciada en la producción del aromático (FIRA, 2016). Ante la presión de los productores y sus asociaciones, la Secretaría de Agricultura, Ganadería, Desarrollo Rural, Pesca y Alimentación [Sagarpa] planteó el Plan Integral de Atención del Café (Sagarpa, 2016a) como una solución a la crisis, bajo una visión productivista clásica: aplicación de tecnología, viveros "tecnificados", fondo de cobertura y renovación de cafetales (Renard y Larroa, 2017). Por medio de la alianza entre dependencias federales y empresas comercializadoras, el PIAC propone duplicar la producción nacional para el ciclo 2018/2019. El énfasis fue hacia la introducción de variedades mejoradas resistentes a la roya, con limitados requerimientos de sombra. La falta de atención a la sombra como una estrategia de conservación de la biodiversidad contradice la Estrategia de Integración para la Conservación y el Uso Sustentable de la Biodiversidad en el Sector Agrícola (2016-2022) (Sagarpa, 2016b), además de no considerar los sistemas productivos en uso en el país y en el estado. En el mismo tenor, el gobierno de Chiapas planteó el Programa Institucional 2013-2018 de la Comisión para el Desarrollo y Fomento del Café de Chiapas, cuyas acciones principales contemplaron la "introducción de plantas de variedades mejoradas y resistentes a las plagas y enfermedades, rehabilitación de cafetales, producción orgánica" (Gobierno de Chiapas, 2012). Similar al caso de la Sagarpa, las variedades introducidas fueron de exposición al sol, con requerimientos mínimos de sombra; contradiciendo así lo 
definido en su Plan Estatal de Manejo Agroecológico del Café en Chiapas (Barrera, Parra-Vázquez, Barrera-Hernández, Jarquín-Gálvez y Pohlan, 2004).

Según documentos del PIAC, se estima que 210000 000 de plantas certificadas fueron sembradas en una superficie de 70000 ha a 80000 ha en el año 2016 (Sagarpa, 2016a). Por otra parte, el gobierno de Chiapas anunció en 2014 la distribución en el sexenio actual de 55000000 de plantas resistentes a la roya como parte del "Programa de Innovación y Transferencia de Tecnología contra la Roya del Cafeto en Chiapas" (Libert, 2014). La colocación de plantas resistentes a la roya se ha realizado también mediante esquemas de crédito refaccionario ofrecidos por empresas comercializadoras de café, preocupadas por asegurar su materia prima. Ejemplos de estas campañas empresariales de renovación de cafetales mediante esquemas financieros con tasas de interés subsidiadas por entes públicos incluyen la campaña "Por más café" de la Exportadora Café California. Otro ejemplo yace en la iniciativa de Starbucks denominada "Todos sembramos café", que propone la donación de una plántula de café resistente a la roya por cada saco de café vendido al consumidor ante el problema de la disminución en $65 \%$ de la producción en Chiapas en los últimos 4 años, según su sitio internet. Mediante esta iniciativa, Starbucks ha donado hasta la fecha 1000000 de plantas de café para un total de 330 ha renovadas en Chiapas; mientras que anuncia la meta de donar 4000000 de plantas para 2021 (Starbucks, s/f). La promoción de nuevas variedades que requieren menos sombra representa en los hechos un cambio de uso de suelo, al cambiar de policultivos bajo sombra diversificada a monocultivos de café de porte bajo y sombra reducida.

Las acciones realizadas por el gobierno federal y estatal para enfrentar la crisis socioecológica de la roya plantean que a pesar de contar con "papeles" de buenas prácticas, sus programas continuaron en la visión clásica productivista, sin considerar los costos ambientales o los impactos en los medios de vida de los productores. El uso de variedades bajo sol altera los medios y estrategias de vida de pequeños productores (superficies reducidas, tecnologías rústicas, manejo tradicional) al requerir mayores insumos de fertilización, control de plagas y enfermedades, manejo de tejidos y labores culturales, principalmente, a cambio de una mayor productividad. Sin embargo, productores indican que una mayor productividad no deriva necesariamente en mejores ingresos, ante el aumento en los costos de producción, problemas con la cosecha de un grano que "pesa menos" y que contiene mucho grano "vano" y un menor precio pagado a la cooperativa por tener un grano de baja calidad en taza.

Según algunos investigadores, la mezcla de variedades con genes resistentes a la roya que ha llegado a poblar la región en el contexto de la epidemia de la roya será una fuerte presión de selección para la evolución genética de Hemileia vastatrix (Avelino y Rivas, 2013). No solo las plantas promovidas han perdido su resistencia a la roya (tal como en el caso de Costa Rica 95, Colombia, Lempira y Oro Azteca), sino que la introducción de plantas de café con genes de resistencia a la roya empuja a este organismo hacia la evolución genética, tal como se confirma con los "rumores" en 2017 en la región de una "nueva” roya más agresiva (La Prensa, 2017; Avelino y Rivas, 2013). De esta manera se vislumbra un problema persistente en el mediano plazo, demostrando que la producción de plantas con resistencia a la roya no es una solución sostenible o resiliente ante la epidemia: prácticas agrícolas como la fitocultura de variedades resistentes y la aplicación de fungicidas y pesticidas puede generar una evolución veloz de especies patógenas (Dwivedi, Sahrawat, Upadhyaya y Ortiz, 2013).

Las propuestas de atención al impacto de las plagas y enfermedades implementadas en Chiapas conducen a incrementar la vulnerabilidad de las poblaciones pobres y marginadas de la región, enfrascándolas en una ruta de desarrollo planteada desde fuera y sin su consulta. El planteamiento de estrategias alternativas para atender los servicios ambientales y los problemas de marginación y pérdida de estilos y medio de vida, entre otros, requiere de nuevos paradigmas ante eventos como la crisis de la roya (Harvey et al., 2008; Chappell et al., 2013).

Para realizar una primera evaluación de los costos asociados a la maladaptación implementada en relación 
con el manejo de la sombra (carbono) en Chiapas, la tabla 1 muestra los almacenes de carbono en la biomasa aérea viva y suelo $(0 \mathrm{~cm}-30 \mathrm{~cm})$, adaptado de Paz (2009). Los datos de la tabla 1 son medidos en campo y representan condiciones promedio obtenidos de diferentes fuentes, los cuales fueron actualizados y usados por Paz et al. (2012), con caracterizaciones de incertidumbre (Covaleda, Paz y de Jong, 2013), en la evaluación de escenarios de mitigación en Chiapas y en la zona. El uso de valores promedio permite una estimación de primer orden de los impactos de la maladaptación y no pretende caracterizar la incertidumbre asociada a los almacenes de carbono (biomasa aérea y suelo) analizados.

Los cambios en los almacenes de carbono asociados a la política implementada de atención al problema de la roya en la Sierra Madre de Chiapas (cambio de cafetal tradicional a cafetal sin sombra) implica una pérdida de 133 t C ha-1 (Tabla 1). En el caso de cambio de actividades por abandono como consecuencia de la infestación de la roya en los cafetales implica pérdidas de 192 t C ha-1 (cambio a milpa) o $172 \mathrm{t} \mathrm{C} \mathrm{ha}^{-1}$ (cambio a potrero), que son procesos de deforestación que pueden considerarse como instantáneos (en términos anuales). El acceso a fondos de apoyos o subsidios en la producción de café no se considera por el cambio de actividad realizada, tampoco se consideran los costos de oportunidad asociados con el cambio del uso de la tierra, ya que lo que se busca repre-

TABla 1. Almacenes de carbono asociados a los usos del suelo ( $\approx 20$ años).

\begin{tabular}{cccc}
\hline Sistema & $\begin{array}{c}\text { Suelo } \\
\left(\mathrm{t} C \mathrm{ha}^{-1}\right)\end{array}$ & $\begin{array}{c}\text { Biomasa aérea } \\
\left(\mathrm{t} \mathrm{C} \mathrm{ha} \mathrm{a}^{-1}\right)\end{array}$ & $\begin{array}{c}\text { Total } \\
\left(\mathrm{t} \mathrm{C} \mathrm{ha} \mathrm{f}^{-1}\right.\end{array}$ \\
\hline $\mathrm{CS}$ & 120 & 007 & 127 \\
$\mathrm{Cl}$ & 130 & 043 & 173 \\
$\mathrm{CT}$ & 180 & 080 & 260 \\
MM & 066 & 002 & 068 \\
PSA & 080 & 008 & 088 \\
\hline
\end{tabular}

Cafetal con sombra de policultivo (tradicional) (CT), Cafetal sin sombra (CS), Cafetal con sombra de Inga (CI), Milpa de maíz (MM), Pastizal sin árboles (PSA). sentar son los costos de las decisiones actuales tomadas por los productores. Usando un precio conservador del valor de una tonelada de bióxido de carbono (carbono multiplicado por un factor de 3.67) de USD 3.00 - escenario bajo - y USD 8.00 - escenario alto - (Hamrick y Gallant, 2017) y una paridad peso-dólar de MXN 19.00; entonces, el caso de quitar la sombra tiene un costo entre MXN 27822 (escenario bajo) y MXN 74192 (escenario alto); el cambio de cafetal rústico bajo sombra a milpa tiene un costo entre MXN 40164 (bajo) y \$107 105 (alto) y el cambio a potrero entre MXN 35980 (escenario bajo) y MXN95 948 (escenario alto). Estos costos fueron obtenidos de considerar el precio del carbono (bióxido de carbono) y las pérdidas de los cambios de actividad.

Considerando los apoyos del gobierno federal y estatal relacionados con medidas para enfrentar el problema de la roya en los cafetales, las cifras presentadas muestran que los productores pierden entre 13 veces (escenario bajo) y 37 veces (escenario alto) lo que reciben para fomentar la práctica de quitar la sombra al utilizar variedades bajo sol. Los cambios de uso del suelo a milpa o potrero implican perdidas entre 15 veces (escenario bajo) y 50 veces (escenario alto) los apoyos susceptibles a recibir en el ejercicio de estas prácticas. Como contexto, por ejemplo, Escobar (2016) ha estimado una tasa de deforestación de 6.4\% (2000-2015) en la región del Soconusco, con una pérdida de alrededor de $50 \%$ de la sombra, que implicaría pérdidas, conservadoramente, de más de 2000000 t de carbono producto de los cambios de cafetales bajo sombra a otros usos.

En relación con la agrobiodiversidad, un inventario de diversidad florística en cafetales de la Sierra Madre de Chiapas realizado en 2016 por parte del Programa Mexicano del Carbono [PMC] (82 sitios de muestreo de 0.1 ha por sitio) reveló la presencia de más de 506 especies de plantas, incluyendo diez especies bajo alguna categoría de protección según la NOM-059-Semarnat-2010 (SánchezSánchez, Libert-Amico y Paz-Pellat, 2016). Esto representa $17 \%$ de las especies registradas en el Inventario Nacional Forestal y de Suelos 2004-2009 (Rojas, Wegier y Ponce, 2014) y 59\% de los taxa registrados en el inven- 
tario estatal de Chiapas (Conafor, 2014). Los análisis presentados muestran importantes pérdidas ambientales asociadas a políticas encaminadas a incrementar la vulnerabilidad de los productores. Contrario a la estrategia actual, el reconocimiento de los servicios ecosistémicos podría ser monetizada en los mercados voluntarios del carbono (Hamrick y Gallant, 2017), sin menoscabo de considerar precios mejores por tener una biodiversidad asociada.

\section{Campaña del PMC: bases para desarrollos futuros}

Ante la amplitud de la crisis socioecológica generada por la epidemia de la roya en México, se consolidó una red interdisciplinaria de investigadores, impulsada por el $\mathrm{PMC}^{3}$ para buscar opciones de atención enfocados en la Sierra Madre de Chiapas.

Construyendo sobre la base de investigación académica realizada en la zona desde 2010 (Paz et al., 2012), se inició un diálogo con actores claves de la región, particularmente las cooperativas de café que venden por medio de las redes de comercio justo, para analizar colectivamente la propuesta. Ante el interés expresado por parte de productores en participar en esta iniciativa de investigación colaborativa, se arrancó con una fase de diagnóstico, juntando trabajo de campo con investigación de gabinete.

La Campaña a favor de los acervos de carbono y la biodiversidad en cafetales bajo sombra: "Una REDD+ para Salvar la Sombra de la Sierra Madre de Chiapas" busca contribuir ante la presente epidemia con datos científicos, amplio trabajo de campo y la construcción de acuerdos con los actores sociales del territorio. Ante una crisis socioecológica en la cual existe poca información, el PMC propuso medir los impactos de la presente epidemia de la roya por medio de la realización de inventarios de carbono y de biodiversidad en diferentes ecosistemas cafetaleros y ex cafetaleros. De esta manera, se espera llenar vacíos de información sobre los impactos de la presente crisis en los almacenes de carbono de esta ecorregión marcada por contar con una alta biodiversidad en sus selvas

3 http://pmcarbono.org/pmc/proyectos/REDD_para_Salvar_la_Sombra_Sierra_Madre_Chiapas.php. medianas, selvas bajas y bosques mesófilos protegidos por parques naturales de competencia federal y estatal.

El complejo panorama de la roya y sus múltiples impactos fueron sistematizados por medio de 102 entrevistas semiestructuradas en 45 localidades de 16 municipios de la zona de estudio (Wong y Libert, 2016). A la par de este proceso se realizaron inventarios de carbono y de diversidad florística en 233 sitios de muestreo a través de la región (Libert-Amico, Wong-González y Paz-Pellat, 2017). Esto sitios siguieron la metodología inspirada en IPCC (2014) y diseñada por el PMC, que incluye la medición del contenido de carbono en todos sus almacenes y la identificación de todas las especies florísticas en un sitio de $1000 \mathrm{~m}^{2}$ (PMC, 2016a, b y c).

En un primer momento, fue clave dilucidar el andamiaje de la roya del café y su impacto en el bienestar económico, social y ambiental de la región. Pérdidas en la producción de café - ingreso principal para esta región montañosa - generan problemas sociales y ambientales. Las acciones de respuesta institucional a la crisis de la roya han fomentado un cambio de uso del suelo en la región. Pérdidas en la producción de café han llevado al abandono de la cafeticultura bajo sombra, remplazando esta por maizales o pastizales (ecosistemas con limitados almacenes de carbono y pocos servicios ecosistémicos debido a la limitada diversidad florística) o a cafetales renovados con variedades resistentes a la roya, que requieren de menos sombra y más insumos externos para su óptima nutrición. En el marco de las discusiones a escala internacional sobre la reducción de emisiones y la conservación de los acervos de carbono en los bosques tropicales, la campaña ante la roya del café en la Sierra Madre resalta la contribución de sistemas agroforestales a la concreción de compromisos internacionales. Una iniciativa internacional que busca innovar ante el amplio desafío del cambio climático es el "Desafío Bonn", un compromiso global para restaurar paisajes, enfatizando aumentar los acervos de carbono más que evitar las emisiones. Como parte de este desafío global, el gobierno de México se comprometió con la Iniciativa 20×20 en la COP de Lima, Perú, a finales de 2014, con la meta de restaurar 8400000 ha 7000000 ha por 
la Sagarpa y 1400000 ha por la Conafor) para el año 2020 (Meli et al., 2017). Los sistemas agroforestales y la integración de plantas perennes en agroecosistemas podrían constituir una herramienta potencial para el cumplimiento de este objetivo. Por ejemplo, en la cuenca El Tablón, municipio de Villaflores, en la Reserva de la Biósfera La Sepultura de la Sierra Madre de Chiapas, productores han fomentado el establecimiento en zonas degradadas de nuevos cafetales con variedades que requieren menos sombra. En este caso, plántulas de las familias Catimor y Sarchimor son empleadas en esquemas de revegetación o restauración productiva en zonas degradadas por actividades de agricultura o ganadería. Acompañada de la correcta asesoría sobre las exigencias particulares de estas variedades en relación con nutrición de suelos, acidez y manejo de tejidos, esta política de restablecer cobertura vegetal en zonas degradadas podría representar un mecanismo de revegetación y restauración productiva, combinando la cafeticultura con el aprovechamiento forestal, capturando carbono en biomasa aérea y suelos donde antes no había árboles ni materia orgánica en los suelos.

En la misma perspectiva, la Sagarpa se comprometió a participar en la "Iniciativa 4/1000: Suelos para la seguridad alimentaria y el clima", un compromiso para incrementar anualmente en $0.4 \%$ el almacén de carbono en los suelos agrícolas. El fomento de plantas perennes en sistemas de producción agrícola (como los sistemas agroforestales) constituyen una herramienta potencial para el cumplimiento de este objetivo, ya que la integración de materia orgánica en los suelos contribuye a este almacén de carbono. Adicionalmente, reconociendo que dos terceras partes de los $2000000 \mathrm{~km}^{2}$ de superficie terrestre del país se encuentra encima de los $1000 \mathrm{~m}$ snm y que $47 \%$ de estos cuentan con pendientes superiores a $27 \%$ (World Bank, 2017), la producción de café es una alternativa de conservación de suelos y combate a la erosión.

Ante el complejo panorama de la epidemia de la roya, la iniciativa de investigación-acción del PMC ha construido con base en datos empíricos y el diálogo continuo con el sector cafetalero una serie de acciones. Estas propuestas buscan fomentar las sinergias entre mitigación y adaptación al cambio climático inherentes a los sistemas agroforestales bajo el lema de "conservar produciendo, producir conservando" (Toledo y OrtizEspejel, 2014).

Si bien la renovación de los cafetales es una urgencia, la elección de variedades de café compatibles con los ecosistemas locales, las redes comerciales y las formas de producción resulta clave. La búsqueda de nuevas variedades resistentes a la roya se justifica al analizar que los cafetales en las Américas emplean menos de una docena de variedades de cafés, derivadas de las primeras especies originalmente traídas al continente por colonos europeos (van der Vossen et al., 2015). Globalmente, la producción comercial de café arábica no cuenta con la diversidad genética necesaria para ser resistente al estrés ambiental que los escenarios de cambio climático futuro pronostican (Bramel, Krishnan, Horna, Lainoff y Montagnon, 2017).

La campaña del PMC propuso la identificación en campo, con base en los saberes locales de los mismos productores, de variedades de café que son tolerantes a la roya, a la vez que son compatibles con el manejo bajo sombra y orgánico y, cuentan con una alta calidad en taza. En colaboración con productores, cooperativas de café y especialistas agrónomos, se ha logrado identificar la existencia de variedades que cumplen con las necesidades de producción y conservación a la vez. De esta manera, la campaña propone un Programa Estratégico de Renovación de Cafetales, clasificando variedades de café por ecosistema (por medio de una zonificación de variedades de café, estructura del cafetal y tipología de productores). Esta estrategia reconoce la demanda creciente, tanto nacional e internacional, del mercado de café, buscando atender dicha demanda con una oferta diversificada.

La iniciativa de investigación-acción plantea actividades que aseguren mejores rendimientos y calidad en la producción, con variedades de café tolerantes a las enfermedades presentes y futuras, manejados bajo indicadores de agrobiodiversidad (Bioversity International, 2017). A la vez, se plantea obtener un mejor precio para el productor, llegando a nuevos nichos de mercado por medio de la 
certificación de cafetales bajo sombra por sus aportaciones en captura de carbono y biodiversidad.

Aparte de buscar una mejor producción y un mejor precio para el café de los productores interesados, la campaña propone mecanismos financieros de diversificación de ingresos. Estos varían desde un pago por servicios ambientales por concepto de agrobiodiversidad, hasta la participación de los productores en mercados de bonos de carbono y el desarrollo de un seguro paramétrico catastrófico que permitiría una compensación financiera ante pérdidas documentadas por concepto de roya del cafeto $\mathrm{u}$ otras plagas o enfermedades.

Sin embargo, para inicios de 2018 la mayor parte de las propuestas de la Campaña "Una REDD+ para Salvar la Selva” están en la etapa de pasar del papel a la acción. A pesar de proveer estudios técnicos que justifiquen la relevancia y pertinencia de las iniciativas, la toma de decisiones en la construcción de políticas gubernamentales no depende exclusivamente de la información y los datos. Falta no solo más trabajo de investigación, sino también la construcción de una plataforma de interlocución y negociación con las instituciones de gobierno y el sector privado, quienes continúan mostrando una falta de transparencia y rendición de cuentas en sus procesos de toma de decisión.

De esta manera, la campaña del PMC se ha dedicado al trabajo de campo y la construcción de acuerdos con el sector cafetalero local, actores de la sociedad civil e instituciones de gobierno para implementar las propuestas de acción. En septiembre de 2017 se realizó la segunda Asamblea de la Campaña a favor de los acervos de carbono y la biodiversidad en cafetales bajo sombra en las instalaciones de la cooperativa Comon Yaj Noptic (Nuevo Paraíso, municipio La Concordia, Chiapas). Esta Asamblea permitió la divulgación y discusión de los resultados de los inventarios de carbono, biodiversidad y análisis de fertilidad de suelos realizados a través de la Sierra Madre de Chiapas (Programa Mexicano del Carbono [PMC], 2017). Adicionalmente, se establecieron acuerdos de seguimiento a la iniciativa de investigación-acción, incluyendo acciones para fortalecer la resiliencia genética de los cafetales bajo sombra por medio de un protocolo científico para la renovación estratégica con variedades de café tolerantes a la roya del cafeto, a la vez que son compatibles con el manejo agroecológico en sistemas agroforestales.

Un tema central del seguimiento de la campaña ha sido la construcción de acuerdos para fortalecer la resiliencia financiera de productores cafetaleros ante eventos climáticos. Esto incluye la colaboración con Agroasemex, S. A., una paraestatal de la Secretaría de Hacienda y Crédito Pública (SHCP). Las sociedades mutualistas de riesgo o fondos de aseguramiento, bajo la tutela de Agroasemex, ofrecen una cobertura de carácter paramétrica (orientada a proteger eventos extremos como plagas y enfermedades) y se encuentra actualmente en operación en predios agropecuarios (Agroasemex, 2006). Como parte de esta iniciativa de investigación-acción, se propone el diseño de un esquema de seguro paramétrico particular ante la roya del cafeto en la Sierra Madre de Chiapas, basado en conocimiento científico y tecnologías satelitales.

Finalmente, en la Asamblea de la Campaña se tomó el acuerdo de seguir promoviendo valor agregado al café y diversificación de ingresos para las comunidades cafetaleras por medio de esquemas de mercados de bonos de carbono y pagos por servicios ecosistémicos, con base en un sistema comunitario de monitoreo de carbono y agrobiodiversidad; una estrategia en proceso de implementación para inicios de 2018.

\section{Discusión: problemas de encaje entre papel y acción}

En este trabajo se presentan una serie de programas, planes y estudios técnicos diseñados en respuesta al cambio climático para la región de estudio, con un enfoque en la actividad cafetalera de la Sierra Madre de Chiapas. Si bien muchos identifican une serie de problemas que atender, a la vez que realizan propuestas de acción, persiste el "problema de encaje" ("problem of fit") entre papel y acción, entre diseño e implementación. De esta revisión sobresalen tres tendencias claves para analizar la relación entre el papel y la acción en la construcción de respuestas al cambio climático; 1) visiones sectoriales que obstaculi- 
zan un análisis integral de la problemática. Los estudios de impacto del cambio climático para el presente tema de interés hablan de un "manejo integrado del territorio", sin embargo, las acciones en el terreno siguen líneas sectoriales (Trench, Larson y Libert, 2017). Si bien la producción de café bajo sombra presenta puentes posibles entre actividades de conservación y producción, los llamados a la visión integral del territorio y la coordinación interinstitucional no han logrado ir más allá de lo discursivo y las buenas intenciones. Mientras abundan las generalidades, otros por su parte se focalizan en buenas prácticas; los programas de respuesta obvian elementos claves para poder justificar acciones prediseñadas, mostrando limitada flexibilidad y resiliencia ante un futuro incierto. El avance paulatino de la epidemia de la roya, desde Colombia en 2008 a Centroamérica a partir de 2010 a Chiapas en 2012 y posteriormente a todos los cafetales del país, ilustra la nula comunicación y baja capacidad de adaptación ante eventos inesperados. Otra deficiencia en el papel mismo es que los planes, programas y estudios tienden a ser diseñados "de arriba hacia abajo", resultando en proyectos exógenos que pueden obviar realidades y particularidades locales, como la especial forma de agricultura de la Sierra Madre de Chiapas y el potencial de los sistemas agroforestales de café en responder a los desafíos futuros; 2) existen amplias barreras para que el papel pueda traducirse en acción. Esto es un desafío clave de la esfera política en general, donde contar con información clara, concisa y de calidad no es suficiente para asegurar una toma de decisiones informada (Plumer, 2017). Una de las debilidades de los llamados "estudios de gabinete" es la desvinculación con la realidad local y la perspectiva de los actores locales; persiste una desunión entre quienes realizan los estudios y la población objetivo de dichos planteamientos. En el marco de los incrementos en el financiamiento disponible para planes y programas en las áreas de cambio climático y desarrollo sostenible, aumentan la cantidad de estudios subcontratados a especialistas externos quienes son contratados puntualmente para realizar en un breve tiempo un registro que llena un vacío identificado en el quehacer de la organización en cuestión.
Este es un ejemplo de lo que se ha llamado la "economía de los pequeños encargos" ("gig economy" en inglés), con un mercado laboral donde prevalecen trabajos temporales y flexibles, en el cual las empresas contratan consultores independientes en vez de empleados de tiempo completo con las correspondientes prestaciones por ley. Esta economía determina los intercambios en los estudios, planes de manejo y programas de respuesta al cambio climático pagados por gobiernos u organizaciones no gubernamentales nacionales e internacionales a consultores independientes, quienes tienden a manejar varios contratos a la vez o estar sin empleo por largos periodos. Esta economía enfocada en productos en vez de procesos ilustra la desvinculación entre estudios, planes y programas y la población afectada por dichos estudios, planes y programas; 3) discrepancias en la transición de papel a la acción. En ocasiones, las acciones implementadas simplemente no toman en consideración los diagnósticos y las recomendaciones de los estudios existentes. La falta de consideración del conocimiento previamente acumulado puede llevar a acciones erróneas que causan más problemas de los que solucionan. Lo última se ilustra en este caso con el ejemplo de la maladaptación a la crisis de la roya del cafeto al delimitar el problema como exclusivamente de productividad. La cadena de valor en el café no es determinada únicamente por el volumen de café cereza, sino también por otras consideraciones tangibles (como la diversificación de ingresos que con el uso de especies útiles como sombra en los cafetales) e intangibles (como la calidad en taza y la provisión de servicios ecosistémicos). La acción propuesta en respuesta a la epidemia de la roya pone en riesgo los beneficios que se derivan de la forma de producción de café bajo sombra diversificada: captura de carbono, hábitats para la biodiversidad, pero también aportaciones a los compromisos internacionales, por ejemplo. A la evaluación de esta acción promulgada sin considerar los diagnósticos y las recomendaciones disponibles, habría que añadir también el impacto de las pérdidas económicas, el aumento en la migración y la presión hacia cultivos ilícitos (elementos difíciles de cuantificar para los fines del presente escrito). 
En la perspectiva anterior, las propuestas de acción informada enfrentan de igual forma una serie de obstáculos, desde la comunicación de la ciencia y la difusión de los resultados, a la construcción de puentes con los actores de la sociedad civil para combinar estudios científicos con presión social. La acción requiere estar basada en información, pero también en diálogos que movilicen las herramientas de la ciencia en colaboración con los conocimientos locales, buscando responder a la coyuntura mediante el diálogo en foros multiactores. De hecho, las acciones que plantea el PMC en la campaña Una REDD+ para Salvar la Sombra arriesgan no poder pasar del papel a la acción. Al ser un proyecto de investigación, cuenta con un plazo limitado de intervención ante la falta de financiamiento y respaldo institucional, mientras que ya de por si la crisis de la roya es una crisis temporal y también ventana de oportunidad para generar cambios que además tiene fecha de caducidad (si bien se teme que otras plagas y enfermedades tomen velozmente el lugar de la roya como determinante de la crisis en el sector cafetalero).

\section{CONCLUSIONES}

Los desafíos que presenta el cambio climático son diversos, intersectoriales y complejos. Mientras que se necesita aumentar la producción agrícola para alimentar una población en crecimiento exponencial, el ampliar la frontera agropecuaria impacta recursos naturales finitos. No obstante, este trabajo postula que la agricultura puede dejar de ser determinante del cambio climático para ofrecer soluciones a la crisis, contribuir a mitigar emisiones y aportar herramientas y capacidades para la adaptación. Adicionalmente, se propone aprender de la estrategia campesina de "no tener todos los huevos en la misma canasta”, adoptando estrategias múltiples para facilitar la diversificación de ingresos en zonas de alta marginación.

Si bien México ha avanzado en mantenerse en las primeras filas de respuesta al cambio climático -sobre todo, en relación con los debates internacionales-, el campo mexicano muestra tener un potencial desaprovechado para aportar herramientas integrales ante los desafíos del cambio climático. Los sistemas agroforestales de café no solo sustentan familias campesinas e indígenas a través del país, resultando viable ser productor del campo en el contexto del minifundismo mexicano, sino también pueden aportar a las acciones necesarias para poder enfrentar los amplios y múltiples desafíos de un futuro incierto. Este trabajo presenta una reflexión sobre la distancia entre papel y acción cuando se refiere a la mitigación y adaptación al cambio climático. Se ilustran los costos de dicho problema de encaje a través de un análisis de la pérdida de servicios ecosistémicos en cafetales bajo sombra ante la promoción de una intensificación productiva en café y simplificación de la estructura de la sombra en estos sistemas agroforestales.

La presente epidemia de la roya del cafeto es un problema complejo: una crisis multifacética con varias causas y diversas consecuencias. La propuesta del PMC identifica aspectos invisibilizados de la crisis, en un contexto donde la atención a la misma ha sido deficiente, causando nuevos problemas hacía el futuro. El reconocimiento de los impactos de dicha epidemia en las emisiones de carbono y la pérdida de biodiversidad permite crear nuevas sinergias institucionales y formas de colaboración multinivel, con el objetivo claro de derivar en resultados concretos a favor de las comunidades cafetaleras, la economía regional y los ecosistemas.

Será clave para el éxito de las propuestas combinar datos duros científicos sobre la magnitud del problema y sus posibles consecuencias, con la presión social de un sector productivo con limitada experiencia de organización social y negociación política, pero una amplia representatividad en el mundo rural e indígena del país.

\section{REFERENCIAS}

Agroasemex. (2006). La experiencia mexicana en el desarrollo y operación de seguros paramétricos orientados a la agricultura. Querétaro: Agroasemex.

Aguilar, S., \& Amezcua, I. (2013a). Plan de adaptación al cambio climático en cooperativas de café Comon Yaj Noptic. San Cristóbal de las Casas, Chis.: Pronatura Sur A.C. y WWF. 
Aguilar, S., \& Amezcua, I. (2013b). Plan de adaptación al cambio climático en cooperativas de café Sociedad de Producción Rural de Responsabilidad Ilimitada Unión Ramal Santa Cruz. San Cristóbal de las Casas, Chis.: Pronatura Sur A.C. y WWF.

Alfaro, J., \& Linne, K. (2008). Adaptación al cambio climático para los pequeños productores. Estrategia de adaptación al cambio climático Más Café, Chiapas. Chiapas: GTZ y Más Café.

Altieri, M., \& Nicholls, C. I. (2017). The adaptation and mitigation potential of traditional agriculture in a changing climate. Climatic Change, 140(1), 33-45. doi: 10.1007/ s10584-013-0909-y

Antwi-Agyei, P., Dougill, A. J., \& Stringer, L.C. (2014). Barriers to climate change adaptation: evidence from northeast Ghana in the context of a systematic literature review. Climate and Development, 7(4): 297-309. doi: $10.1080 / 17565529.2014 .951013$

Atangana, A., Khasa, D., Chang, S., \& Degrande, A. (2014). Agroforestry for soil conservation. En A. Atangana, D. Khasa, S. Chang, \& A. Degrande. Tropical Agroforestry (pp. 203-216). Dordrecht: Springer. doi: 10.1007/978-94007-7723-1_9

Avelino, J., Cristancho, M., Georgiou, S., Imbach, P., Aguilar, L., Bornemann, G., Läderach, P., Anzueto, F., Hruska, A., \& Morales, C. (2015). The coffee rust crisis in Colombia and Central America (2008.2013): impacts, plausible causes and proposed solutions. Food Security, 7(2), 303321. doi: 10.1007/s12571-015-0446-9

Avelino, J., \& Rivas, G. (2013). La roya anaranjada del cafeto. Versión electrónica n.1 (3 de diciembre). HAL. Recuperado de https://hal.archives-ouvertes.fr/hal-01071036

Avelino, J., Muller, R., Eskes, A. B., Santacreo, R., \& Holguín, F. (1999). La roya anaranjada del cafeto: mito y realidad. En B. Bertrand, \& B. Rapidel (eds.), Desafíos de la cafeticultura en Centroamérica (pp. 193-241). San José, Costa Rica, Instituto Interamericano de Cooperación para la Agricultura [IICA]; Promecafe; Cirad; IRD; CCCR-Francia.

Baca, M., Läderach, P., Ovalle, D., Ocón, S., Gomez, L., Garcia, S., \& Carmona, S. (2012). Vulnerabilidad y estrategias de adaptación al cambio climático en los medios de vida de las familias cafetaleras de México. Managua, Nicaragua: Centro Internacional de Agricultura Tropical.

Baker, P. (2014). The 'Big Rust': an update on the coffee leaf rust situation. Coffee \& Cocoa International, 40(6), 37-39.

Barradas, V. L., \& Fanjul, L. (1984). La importancia de la cobertura arbórea en la temperatura del agroecosistema cafetalero. Biotica, 9, 415-421.

Barrera, J., Avelino, J., Huerta, G., Herrera, J., \& Gómez, J. (2013). La roya del café: crónica de una devastación anunciada. Ecofronteras, 49, 22-25.

Barrera, J. F., Parra-Vázquez, M., Barrera-Hernández, O. B., Jarquín-Gálvez, R., \& Pohlan, J. (2004). Plan estatal de manejo agroecológico del café en Chiapas: guía hacia una cafeticultura sustentable. Tapachula, Chiapas: Comisión para el Desarrollo y Fomento del Café de Chiapas-El Colegio de la Frontera Sur.

Bebber, D. P., Castillo, Á. D., \& Gurr, S. J. (2016). Modelling coffee leaf rust risk in Colombia with climate reanalysis data. Philosophical Transactions of the Royal Society B: Biological Sciences, 371, 20150458. doi: 10.1098/ rstb.2015.0458. doi: 10.1098/rstb.2015.0458

Beer, J., Muschler, R., Kass, D., \& Somarriba, E. (1998). Management in coffee and cacao plantations. Agroforestry Systems, 8, 139-164. doi: 10.1023/A:1005956528316

Bioversity International (2017). Mainstreaming Agrobiodiversity in Sustainable Food Systems: Scientific Foundations for an Agrobiodiversity Index. Bioversity International, Rome.

Boonstra, W. J. (2016). Conceptualizing power to study socialecological interactions. Ecology and Society, 21(1), 21. doi: 10.5751/ES-07966-210121.

Bramel, P., Krishnan, S., Horna, D., Lainoff, B., \& Montagnon, C. (2017). Global conservation strategy for coffee genetic resources 2017. Crop Trust y World Coffee Research. Recuperado de https://worldcoffeeresearch.org/documents/42/Coffee_Strategy_Low_Res.pdf.

Carrillo, J. C., \& Ramírez, A.V. (2016). Estudio legal: Facultades y responsabilidades del manejo forestal y del suelo ante REDD+ en México. Documento Ocasional 150. Bogor, Indonesia: Cifor. doi: 10.17528/cifor/006024 
Centro Mexicano de Derecho Ambiental, A. C. [Cemda]. (2016). Arranca la COP13 con nuevas Áreas Naturales Protegidas para México, ¿y los recursos para gestionarlas, cuándo?. 5 diciembre. Recuperado de http://www. cemda.org.mx/arranca-la-cop13-con-nuevas-areas-naturales-protegidas-para-mexico-y-los-recursos-para-gestionarlas-cuando/.

Chappell, M. J., Wittman, H., Bacon, C. M., Ferguson, B., Gracia, L., Garcia, R., Jaffee, D., Lima, J., Mendez, V. E., Morales, H., Soto, L., Vandermeer, J., \& Perfecto, I. (2013). Food sovereignty: an alternative paradigm for poverty reduction and biodiversity conservation in Latin America. F100Research, 2, 325. doi: 10.12688/ f1000research.2-235vi

CI México A. C. (2011). Estrategia del sector cafetalero para la adaptación, mitigación y reducción de la vulnerabilidad ante el cambio climático en la Sierra Madre de Chiapas. Tuxtla Gutiérrez, Chiapas: Conservation International Mexico, A. C.

Clar, C., Prutsch, A., \& Steurer, R. (2013). Barriers and guidelines for public policies on climate change adaptation: A missed opportunity of scientific knowledge brokerage. Natural Resources Forum, 37, 1-18. doi: 10.1111/14778947.12013

Clément, V., \& Rivera, J. (2017). From adaptation to transformation: an extended research agenda for organizational resilience to adversity in the natural environment. Organization \& Environment, 30(4), 346-365. doi: $10.1177 / 1086026616658333$

Convención Marco de las Naciones Unidas sobre Cambio Climático [Cmnucc]. (2015). Adoption of the Paris Agreement. Report No. FCCC/CP/2015/L.9/Rev.1. Recuperado de http://unfccc.int/resource/docs/2015/cop21/eng/109r01.pdf.

Comisión Nacional Forestal [Conafor]. (2017). Estrategia Nacional para REDD+. Zapopan, Jalisco. Recuperado de http://www.conafor.gob.mx/web/temas-forestales/bycc/ redd-en-mexico/estrategia-nacional-redd-enaredd/.

Comisión Nacional Forestal [Conafor]. (2016). Documento de la Iniciativa de Reducción de Emisiones [IRE]. Documento preparado para Forest Carbon Partnership Facility (FCPC) Zapopan, Jalisco, México: Carbon Fund.
Comisión Nacional Forestal [Conafor]. (2014). Inventario Estatal Forestal y de Suelos del estado de Chiapas. Guadalajara, Jalisco, México: Secretaría de Medio Ambiente y Recursos Naturales. Gobierno del Estado de Chiapas.

Comisión Nacional de Áreas Naturales Protegidas [Conanp] Fondo Mexicano para la Conservación de la Naturaleza, A. C. [FMCN] - TNC. (2011). Programa de adaptación al cambio climático en áreas naturales protegidas del complejo Sierra y Costa de Chiapas. México, D.F.: Comisión Nacional de Áreas Nacionales Protegidas.

Concheiro, L., \& Robles, H. (2014). Tierra, territorio y poder a cien años de la reforma agraria en México: Lucha y resistencia campesindia frente al capital. En G. Almeyra, L. Concheiro, J. M. Mendes, \& C. W. Porto-Gonçalves (eds.), Capitalismo: Tierra y poder en América Latina (1982-2012) (pp. 181-224). Vol. III. Ciudad de México, México: UAM.

Cooperativa AMBIO S. C. (2015). El programa de inversión en el marco de la Iniciativa de Reducción de Emisiones en la región de la Fraylesca en el estado de Chiapas. San Cristóbal de Las Casas, Chiapas: USAID/M-REDD+.

Covaleda, S., Aguilar, S., Ranero, A., Marín, I., \& Paz, F. (2014). Diagnóstico sobre determinantes de deforestación en Chiapas. Reporte preparado para la Alianza México-REDD+. Chiapas, México: Tuxtla Gutiérrez.

Covaleda, C., Paz, F., \& de Jong, B. (2013). Parametrización de modelos de estados y transiciones para el carbono y caracterización de la incertidumbre. En F. Paz, M. Bazan, \& V. Saynes (eds.), Dinámica del Carbono en el Suelo 2012. Serie Avances Temáticos del Ciclo del Carbono y sus Interacciones (pp. 85-91). Texcoco, Estado de México, México: Programa Mexicano del Carbono - Sociedad Mexicana de Ciencias del Suelo.

Crédit Suisse. (2015). Global Wealth Report 2015. Crédit Suisse A. G.

CRUO-UACh-INCA Rural-Amecafé-Sistema Producto Café. 2011. Plan de innovación de la cafeticultura en el estado de Chiapas. Tuxtla Gutiérrez, Chiapas, México.

Dalberg. (2012). Catalyzing smallholder agricultural finance. Nueva York: Citi y Skoll. 
Dwivedi, S., Sahrawat, K., Upadhyaya, H., \& Ortiz, R. (2013). Food, Nutrition and Agrobiodiversity Under Global Climate Change. Advances in Agronomy, 120, 1-128. doi: 10.1016/B978-0-12-407686-0.00001-4

Escamilla, E., Ortiz, O., Diaz, G., Landeros, C., Platas, D. E., Zamarripa, A., \& González, V. A. (2005). El agroecosistema café orgánico en México. Manejo Integrado de Plagas y Agroecología, 76, 5-16.

Escamilla-Prado, E., Ruiz-Rosado, O., Zamarripa-Colmenero, A., \& González-Hernández, V. A. (2016). Calidad en variedades de café orgánico en tres regiones de México. Revista de Geografía Agrícola, 55, 45-55.

Escobar, R. E. (2016). Análisis del cambio en la cobertura y uso del suelo en el Soconusco, Chiapas. (Tesis de maestría). San Cristóbal de las Casas, Chiapas, México: El Colegio de la Frontera Sur.

Fideicomisos Instituidos en Relación con la Agricultura [FIRA]. (2012). Panorama agropecuario: Café, 2012/2013. México: Dirección General Adjunta de Inteligencia Sectorial, Fideicomisos Instituidos en Relación con la Agricultura.

Fideicomisos Instituidos en Relación con la Agricultura [FIRA]. (2016). Panorama agropecuario: Café 2016. México: Dirección de Investigación y Evaluación Económica y Sectorial, Fideicomisos Instituidos en Relación con la Agricultura.

Galaz, V., Olsson, P., Hahn, T., Folke, C., \& Svedin, U. (2008). The problem of fit among biophysical systems, environmental and resource regimes, and broader governance systems: insights and emerging challenges. En O. R. Young, L.A. King, \& H. Schroeder (eds.), Institutions and environmental change. Principal findings, applications and research frontiers (pp. 147-186). Massachusetts, USA: MIT, doi: 10.7551/mitpress/9780262240574.003. 0005

Galloway, J. N., Townsend, A. R., Erisman, J. W., Bekunda, M., Cai, Z., Freney, J. R., Martinelli, L. A., Seitzinger, S. P., \& Sutton, M. A. (2008). Transformation of the Nitrogen Cycle: Recent Trends, Questions, and Potential Solutions. Science, 16, 889-892. doi: 10.1126/ science. 1136674
Gobierno de Chiapas. (2011). Programa de acción ante el cambio climático del estado de Chiapas. Tuxtla Gutiérrez, Chiapas, México: Gobierno de Chiapas.

Gobierno de Chiapas. (2012). Programa institucional. Tuxtla Gutiérrez, Chiapas, México: Comisión para el Desarrollo y Fomento del Café de Chiapas (Comcafe) 2013-2018.

Gobierno de Chiapas. (2013). Programa regional de desarrollo 2013-2018 Región IX Istmo Costa. Tuxtla Gutiérrez, Chiapas, México: Gobierno de Chiapas.

Godfray, H. C. J., \& Garnett, T. (2014). Food security and sustainable intensification. Philosophical Transactions of the Royal Society, B 369, 20120273. doi: 10.1098/ rstb.2012.0273.

González, M. A. A., Enríquez, P. L., Rangel, J. L., García, C., \& Tejeda, C. (2012). Contribución de la riqueza y la diversidad de aves en plantaciones de café de sombra del sureste de México. Tropical and Subtropical Agroecosystems, 15, 629-647.

Hamrick, K., \& Gallant, M. (2017). Unlocking potential: state of the voluntary carbon markets 2017. Ecosystem Marketplace.

Harvey, C. A., Komar, O., Chazdon, R., Ferguson, B. G., Finegan, B., Griffith, D. M., Martinez, M., Morales, H., Nigh, R., Soto, L., van Breugel, M., \& Wishnie, M. (2008). Integrating agricultural landscapes with biodiversity conservation in the Mesoamerican hotspot. Conservation Biology, 22, 8-15. doi: 10.1111/j.1523-1739.2007.00863.x

Haunschild, R., Bornmann, L., \& Marx, W. (2016). Climate change research in view of bibliometrics, PLoS ONE, 11(7), e0160393. doi: 10.1371/journal.pone.0160393

International Coffee Organization [ICO]. (2017). Total production by all exporting countries. Recuperado de http:// www.ico.org/trade_statistics.asp.

Imbach, P., Beardsley, M., Bouroncle, C., Medellin, C., Läderach, P., Hidalgo, H., Alfaro, E., Van Etten, J., Allan, R., Hemming, D., Stone, R., Hannah, L., \& Donatti, C. (2017). Climate change, ecosytems and smallholder agriculture in Central America: an introduction to the special issue. Climatic Change, 141, 1-12. doi: 10.1007/s10584017-1920-5. 
Intergovernmental Panel on Climate Change [IPCC]. (2014). Climate Change 2014: Impacts, Adaptation, and Vulnerability. Part A: Global and Sectoral Aspects. En C. B. Field, V. R. Barros, D. J. Dokken, K. J. Mach, M. D. Mastrandrea, T. E. Bilir, M. Chatterjee, K. L. Ebi, Y. O. Estrada, R. C. Genova, B. Girma, E. S. Kissel, A. N. Levy, S. MacCracken, P.R. Mastrandrea, and L.L. White (eds.), Contribution of Working Group II to the Fifth Assessment Report of the Intergovernmental Panel on Climate Change. New York: Cambridge University Press.

Jha, S., Bacon, C., Philpott, S., Méndez, E., Läderach, P., \& Rice, R. (2014). Shade coffee: update on a disappearing refuge for biodiversity. Bioscience, 64(5), 416-428. doi: 10.1093/biosci/biu038.

Jönsson, A. M., Anderbrant, O., Holmer, J., Johansson, J., Schurgers, G., Svensson, G. P., \& Smith, H. G. (2015). Enhanced science-stakeholder communication to improve ecosystem model performances for climate change impact assessments. AMBIO, 44, 249-255. doi: 10.1007/s13280014-0553-4.

Kibeltik Clima y Medio Ambiente A. C. (2016). Programa de inversión de la región Istmo-Costa en el estado de Chiapas. San Cristóbal de Las Casas, Chiapas, México.

Kolbert, E. (2014). The Sixth Extinction: an unnatural history. Nueva York, EUA: Henry Holt and Co,

Kongsager, R., Locatelli, B., \& Chazarin, F. (2016). Addressing Climate Change Mitigation and Adaptation Together: A Global Assessment of Agriculture and Forestry Projects. Environmental Management, 57, 271-282. doi: 10.1007/ s00267-015-0605-y.

La Prensa. (2017). Nueva raza de roya causará hambruna en zonas cafetaleras. 5 de abril. Recuperado de http://www. laprensa.hn/honduras/1060126-410/nueva-raza-de-royacausar\%C3\%A1-hambruna-en-zonas-cafetaleras.

Läderach, P., Haggar, J., Lau, C., Eitzinger, A., Ovalle, O., Baca, M., Jarvis, A., \& Lundy, M. (2013). Café mesoamericano: Desarrollo de una estrategia de adaptación al cambio climático. CIAT Políticas en Síntesis No. 2. Cali, Colombia: Centro Internacional de Agricultura Tropical [CIAT].

Lasco, R. D., Delfino, R. J. P., \& Espaldon, M. L. O. (2014). Agroforestry systems: helping smallholders adapt to cli- mate risks while mitigating climate change. WIREs Clim Change, 5(6), 825-833. doi: 10.1002/wcc.301

Libert-Amico, A., Wong-González, J. C., \& Paz-Pellat, F. (2017). Impacto de la roya del cafeto en los almacenes de carbono en la Sierra Madre de Chiapas. En: F. Paz, \& R. Torres (eds.), Estado Actual del Conocimiento del Ciclo del Carbono y sus Interacciones en México: Síntesis a 2016 (pp. 219-225). Texcoco, Estado de México, México: Programa Mexicano del Carbono-Universidad Autónoma del Estado de Hidalgo.

Libert-Amico, A. (2017). La preparación ante un futuro incierto: respuestas al cambio climático en la Sierra Madre de Chiapas, México. (Tesis de doctorado). UAMXochimilco, Ciudad de México, México.

Libert-Amico, A., \& Trench, T. (2016). Bosques y suelos en el contexto de REDD+: Entre gobierno y gobernanza en México. Terra Latinoamericana, 34, 113-124.

Libert, A. (2014). Los desafíos que plantea el cambio climático a la relación entre sociedad y naturaleza: una mirada desde Chiapas. En B. Rodríguez, \& O. Contreras (eds.), La construcción del futuro: los retos de las ciencias sociales en México (pp. 499-510). Tuxtla Gutiérrez, Chiapas, México: Cesmeca-Unicach,

López, G., Sotomayor, D., Amador, J. A., \& Shröder, E. C. (2015). Contribution of nitrogen from litter and soil mineralization to shade and sun coffee (Coffea arabica L.) agroecosystems. Tropical Ecology, 56, 155-167.

Lowder, S. K., Skoet, J., \& Raney, T. (2016). The number, size, and distribution of farms, smallholder farms, and family farms worldwide. World Development, 87, 16-29. doi: 10.1016/j.worlddev.2015.10.041.

Lyle, G. (2015). Understanding the nested, multi-scale, spatial and hierarchical nature of future climate change adaptation decision making in agricultural regions: A narrative literature review. Journal of Rural Studies, 37, 38-49. doi: 10.1016/j.jrurstud.2014.10.004.

McCook, S., \& Vandermeer, J. (2015). The Big Rust and the Red Queen: Long-Term Perspectives on Coffee Rust Research. Phytopathology, 105(9), 1164-1173. doi: 10.1094/PHYTO-04-15-0085-RVW.

McCook, S. (2013). The ecology of taste: Robusta coffee and the limits of the specialty revolution. En R. W. Thurston, 
J. Morris, \& S. Steiman (eds.), Coffee: a comprehensive guide to the bean, the beverage, and the industry (pp. 248-261). Lanham: Rowman \& Littlefield.

McCook, S. (2009). La roya del café en Costa Rica: epidemias, innovación y medio ambiente, 1950-1995. Revista Historia, (59-60), 99-117.

Meli, P., Herrera, F. F., Melo, F., Pinto, S., Aguirre, N., Musálem, N., Minaverry, C., Ramírez, W., \& Brancalion, P. (2017). Four approaches to guide ecological restoration in Latin America. Restoration Ecology, 25(2), 156-163. doi: 10.1111/rec.12473

Méndez, V. E., \& Bacon, C. M. (2006). Ecological processes and farmer livelihoods in shaded coffee production. LEISA Magazine, 22(4), 22-23.

Moguel, P., \& Toledo, V. M. (1999). Biodiversity conservation in traditional coffee systems of Mexico. Conservation Biology,13,11-21.doi:10.1046/j.1523-1739.1999.97153.x

Morison, J. I. L., Baker, N. R., Mullineaux, P. M., \& Davies, W. J. (2008). Improving water use in crop production. Philosophical Transactions of the Royal Society B, 363(1491). doi :10.1098/rstb.2007.2175.

Munck af Rosenschöld, J., Rozema, J. G., \& Frye-Levine, L. A. (2014). Institutional inertia and climate change: a review of the new institutionalist literature. WIREs Clim Change, 5, 639-648. doi: 10.1002/wcc.292.

Paz, F. (2009). Una REDD para Chiapas (bases metodológicas y estrategias de implementación). Borrador 0.5. San Cristóbal de Las Casas, Chis. Recuperado de http://pmcarbono. org/pmc/biblioteca/articulos_socios.php.

Paz, F., Covaleda, S., Ranero, A., Ugarte, X., Esquivel, E., Marín, M. I., Cuevas, R., de Jong, B., \& Etchevers, J. D. (2012). Estudio de Factibilidad para el mecanismo $R E D D+$ en Chiapas. Informe preparado para Conservation International México. Tuxtla Gutiérrez, Chiapas, México: Programa Mexicano del Carbono.

Picketty, T. (2014). El capital en el siglo XXI. México, D. F.: Fondo de Cultura Económica.

Plumer, B. (2017). A climate science report that changes minds? Don't bet on it. The New York Times, 4 de noviembre.

Programa Mexicano del Carbono [PMC]. (2016a). Una REDD para SALVAR la SOMBRA de la Sierra Madre de Chia- pas. Manual de Procedimientos Inventario de Carbono+. F. Paz (coord.). A. Libert, J. C. Wong, \& F. Rojas (colabs.). Texcoco, Estado de México, México.

Programa Mexicano del Carbono [PMC]. (2016b). Una REDD para SALVAR la SOMBRA de la Sierra Madre de Chiapas. Manual de Procedimientos Inventario de Biodiversidad. F. Paz (coord.). A. Libert, J. C. Wong, \& C. D. Sánchez (colabs.). Texcoco, Estado de México, México.

Programa Mexicano del Carbono [PMC]. (2016c). Una REDD para SALVAR la SOMBRA de la Sierra Madre de Chiapas. Manual de Procedimientos Inventario Rápido de Carbono+. Red de Puntos de Control. Coordinador: F. Paz (coord.). A. Libert, \& J. C. Wong (colabs.). Texcoco, Estado de México, México.

Programa Mexicano del Carbono [PMC]. (2017). Resiliencia de las organizaciones de productores agroforestales ante el cambio climático: intercambio entre cooperativas de la Selva Lacandona y de la Sierra Madre de Chiapas. Recuperado de http://pmcarbono.org/pmc/descargas/proyectos/redd/Reporte_Taller_IICA-PMC_21-22sept2017.pdf.

Promecafe - IICA. (2013). Las crisis del café en Mesoamérica: causas y respuestas apropiadas. Instituto Interamericano de Cooperación para la Agricultura. San José, Costa Rica.

Qualset, C.O., \& Shands, H. (2005). Safeguarding the future of US agriculture: The need to conserve threatened collections of crop diversity worldwide. Davis, CA: University of California-Genetic Resources Conservation Program, USA.

Ranero, A., Covaleda, S., Montero, J. A., Amezcua, U., Esquivel, E., Lara, M., Thompson, C., Bejarano, M., Arnaiz, E., \& Andrade, R. (2017). Documento de la estrategia estatal REDD+ del estado de Chiapas (marzo 2017). San Cristóbal de Las Casas, Chiapas, México.

Renard, M.-C., \& Larroa T., R. M. (2017). Política Pública y sustentabilidad de los territorios cafetaleros en tiempos de roya: Chiapas y Veracruz. Estudios Latinoamericanos, 40, 95-113.

Robles, H., Suárez, V., \& de la Mora, D. (2015). Reporte: Iniciativa Valor al Campesino. Recuperado de http://subsidiosalcampo.org.mx/wp-includes/textos_pdf/Valor_al_ Campesino_Reporte_completo.pdf. 
Rockström, J., Williams, J., Daily, G., Noble, A., Matthews, N., Gordon, L., Wetterstrand, H., DeClerck, F., Shah, M., Steduto, P., de Fraiture, Ch., Hatibu, N., Unver, O., Bird, J., Sibanda, L., \& Smith, J. (2016). Sustainable intensification of agriculture for human prosperity and global sustainability. Ambio, 46, 4-17. doi: 10.1007/ s13280-016-0793-6.

Rodrigues Jr., C. J., Bettencourt, A. J., \& Rijo, L. (1975). Races of the pathogen and resistance to coffee rust. Annual Review of Phytopathology, 13, 49-70. doi: 10.1146/annurev.py.13.090175.000405.

Rojas, F., Wegier, A., \& Ponce, A. (2014). Evaluación cuantitativa de errores en la nomenclatura científica del Inventario Nacional Forestal y de Suelos 2004-2009. Terra Latinoamericana, 32, 325-331.

Rojas, A., Hartman, K., \& Almonacid, R. (2012). El impacto de la producción de café sobre la biodiversidad, la transformación del paisaje y las especies exóticas invasoras. Ambiente y Desarrollo, 16, 93-104.

Rozo, Y., Escobar, C., Gaitán, Á., \&. Cristancho, M. (2012). Aggressiveness and genetic diversity of Hemileia vastatrix during an epidemic in Colombia. Journal of Phytopathology, 160, 732-740. doi: 10.1111/jph.12024.

Ruiz, J. A., Bravo, E., Ramírez, G., Báez, A. D., Álvarez, M., Ramos, J. L., Nava, U., \& Byerl, K. F. (2013). Plagas de importancia económica en México: aspectos de su biología y ecología. Libro Técnico Núm. 2. Tepatitlán de Morelos, Jalisco, México: Inifap-Cirpac-Campo Experimental Centro Altos de Jalisco. 447 p.

Secretaría de Agricultura, Ganadería, Desarrollo Rural, Pesca y Alimentación [Sagarpa] (2016a). Plan Integral de Atención al Café (ppt). Recuperado de http://www.cmdrs.gob. mx/comisiones/COPSP/Documents/2016/15a_extra/piac. pdf.

Secretaría de Agricultura, Ganadería, Desarrollo Rural, Pesca y Alimentación [Sagarpa] (2016b). Estrategia de integración para la conservación y el uso sustentable de la biodiversidad en el sector agrícola (2016-2022). México, D. F.: Sagarpa.

Sánchez-Sánchez, C., Libert-Amico, A., \& Paz-Pellat, F. (2016). Biodiversidad en cafetales. Sexto Informe de la campaña
Una REDD para Salvar la Sombra. Programa Mexicano del Carbono, Texcoco, Estado de México, México.

Schader, C., Muller, A. El-Hage Scialabba, N., Hecht, J., Isensee, A., Erb, K-H., Smith, P., Makkar, H., Klocke, P., Leiber, F., Schwegler, P., Stolze, M., \& Niggli, U. (2015). Impacts of feeding less food-competing feed-stuffs to livestock on global food system sustainability. Journal of the Royal Society Interface, 12, 20150891. doi: 10.1098/ rsif.2015.0891.

Schroth, G., Laderach, P., Dempewolf, J., Philpott, S., Haggar, J., Eakin, H., Catillejos, T., Garcia, J., Soto, L., Hernandez, R., Eitzinger, A., \& Ramirez, J. (2009). Towards a climate change adaptation strategy for coffee communities and ecosystems in the Sierra Madre of Chiapas, Mexico. Mitigation and Adaptation Strategies for Global Change, 14(7), 0605-625. doi: 10.1007/s11027-009-9186-5.

Skutsch, M., Balderas-Torres, A., \& Carrillo-Fuentes, J. C. (2017). Policy for pro-poor distribution of REDD+ benefits in Mexico: How the legal and technical challenges are being addressed. Forest Policy and Economics, 75, 58-66. doi: 10.1016/j.forpol.2016.11.014

Solano-Vidal, R. (2017). Situación actual de las razas fisiológicas de la roya (Hemileia vastratrix) del cafeto y un nuevo sistema de nomenclatura. Revista Mexicana de Fitopatología, 35(suplemento), 28-31.

Soto, L., \& Aguirre, C. M. (2015). Carbon stocks in organic coffee systems in Chiapas, Mexico. Journal of Agricultural Science, 7, 117-127. doi: 10.5539/jas.v7n1p117

Soto, L. (2013). El café y la biodiversidad asociada. En Comisión Nacional para el Conocimiento y Uso de la Biodiversidad [Conabio] y Gobierno del Estado de Chiapas, La Biodiversidad en Chiapas: Estudio de Estado (pp. 198200). México.

Soto, L., Anzueto, M., Mendoza, J., Jimenez, G., \& de Jong, B. (2010). Carbon sequestration through agroforestry in indigenous communities of Chiapas, Mexico. Agroforestry Systems, 78, 39-51. doi: 10.1007/s10457-009-9247-5

Soto, L., Romero, Y., Caballero, J., \& Segura, G. (2001). Woody plant diversity and structure of shade-ground-coffee plantations in Northern Chiapas, Mexico. Revista de Biología Tropical, 49, 977-987. 
Taylor, M. (2015). The political ecology of climate change adaptation. Livelihoods, agrarian change and the conflicts of development. Nueva York, EUA: Routledge.

Toledo, V. M., \& Ortiz-Espejel, B. (2014). México, regiones que caminan hacia la sustentabilidad. Una geopolítica de las resistencias bioculturales. Puebla, Puebla, México: Universidad Iberoamericana.

Toledo, V. M., \& Moguel, P. (2012). Coffee and sustainability, the multiples values of traditional shaded coffee. Journal of Sustainable Agriculture, 36, 353-377. doi: 10.1080/10440046.2011.583719

Trench, T., Larson, A. M., \& Libert, A. (2017). Multilevel governance and land use in Chiapas and Yucatan. Lessons for REDD+ in Mexico. Bogor: Cifor. doi: 10.17528/ cifor/006550

United Nations Development Programme [UNDP] (2007). Fighting climate change: human solidarity in a divided world, Human Development Report 2007/8, Palgrave Macmillan, Nueva York. doi: 10.1057/9780230598508_1

van der Vossen, H., Bertrand, B., \& Charrier, A. (2015). Next generation variety development for sustainable production of arabica coffee (Coffea arabica L.): a review. Euphytica, 204, 243-256. doi: 10.1007/s10681-015$1398-z$.

van Rikxoort, H., Schroth, G., Läderach, P., \& Rodríguez-Sánchez, B. (2014). Carbon footprints and carbon stocks reveal climate-friendly coffee production. Agronomy for Sustainable Development, 34, 887-897. doi: 10.1007/ s13593-014-0223-8

Vandermeer ,J. H., \& Perfecto, I. (2012). Syndromes of Production in Agriculture: Prospects for Social-Ecological Regime Change. Ecology and Society, 17(4). doi: 10.5751/ ES-04813-170439.

Vink, M. J., Dewulf, A., \& Termeer, C. (2013). The role of knowledge and power in climate change adaptation governance: a systematic literature review. Ecology and Society, 18(4), 46. doi: 10.5751/ES-05897-180446.

Wong, J. C., \& Libert, A. (2016). Planeación de la campaña de campo para cafetales de la Sierra Madre de Chiapas. Cuarto Informe de la Campaña Una REDD para Salvar la Sombra. Texcoco: Programa Mexicano del Carbono. Recuperado de http://pmcarbono.org/pmc/descargas/proyectos/redd/4to_Informe_Roya-Cafe_Chiapas+Planea cion_campa_de_campo.pdf.

World Bank. (2017). Climate Change Knowledge Portal: Mexico Dashboard. Washington D. C.: World Bank. Recuperado de http://sdwebx.worldbank.org/climateportalb/home.cfm? page $=$ country_profile $\&$ CCode $=$ MEX .

World Bank. (2012). Turn down the heat: why a $4{ }^{\circ} \mathrm{C}$ warmer world must be avoided (English). Washington D. C.: World Bank. Recuperado de http://documents.worldbank.org/curated/en/865571468149107611/Turn-downthe-heat-why-a-4-C-warmer-world-must-be-avoided.

Zomer, R. J., Neufeldt, H., Xu, J., Ahrends, A., Bossio, D., Trabucco, A., van Noordwijk, M., \& Wang, M. (2016). Global tree cover and biomass carbon on agricultural land: the contribution of agroforestry to global and national carbon budgets. Scientific Reports, 6, 29987. doi: 10.1038/srep29987.

Manuscrito recibido el 21 de diciembre de 2017

Aceptado el 6 de abril de 2018

Publicado el 18 de diciembre de 2018

Este documento se debe citar como:

Libert-Amico, A., \& Paz-Pellat, F. (2018). Del papel a la acción en la mitigación y adaptación al cambio climático: la roya del cafeto en Chiapas. Madera y Bosques, 24(Núm. esp.), 2401914. doi: 10.21829/ myb.2018.2401914

Madera y Bosques por Instituto de Ecología, A.C. se distribuye bajo una Licencia Creative Commons Atribución-No Comercial-Compartir Igual 4.0 Internacional. 